Trinity University

Digital Commons @ Trinity

\title{
$5-2014$
}

\section{Developing Scientific Literacy in Introductory Laboratory Courses: A Model for Course Design and Assessment}

\author{
Benjamin E. Surpless \\ Trinity University, bsurples@trinity.edu \\ Michelle M. Bushey \\ Trinity University, mbushey@trinity.edu \\ M. Halx
}

Follow this and additional works at: https://digitalcommons.trinity.edu/geo_faculty

Part of the Earth Sciences Commons

\section{Repository Citation}

Surpless, B. E., Bushey, M., \& Halx, M. (2014). Developing scientific literacy in introductory laboratory courses: A model for course design and assessment. Journal of Geoscience Education, 62(2), 244-263. doi: $10.5408 / 13-073.1$

This Article is brought to you for free and open access by the Geosciences Department at Digital Commons @ Trinity. It has been accepted for inclusion in Geosciences Faculty Research by an authorized administrator of Digital Commons@ Trinity. For more information, please contact jcostanz@trinity.edu. 


\title{
Developing Scientific Literacy in Introductory Laboratory Courses: A Model for Course Design and Assessment
}

\author{
Benjamin Surpless, ${ }^{1, a}$ Michelle Bushey, ${ }^{2}$ and Mark Halx ${ }^{3}$
}

\begin{abstract}
Although science educators at all levels have focused on teaching students scientific literacy for nearly five decades, studies indicate that the average student remains far from scientifically literate. To address this issue at the local level, faculty at Trinity University, in San Antonio, Texas, significantly revised the curriculum of an existing introductory physical geology laboratory course. The course, which satisfies general education requirements at Trinity, was revised to provide students learning opportunities in a scientific process context as part of a new science literacy initiative. This effort was spurred by general dissatisfaction with the existing curricular structure of the course as well as a new interdisciplinary, National Science Foundation (NSF)-funded initiative to support the integration of research-grade instrumentation in curricula and undergraduate research across campus. The physical geology laboratory course revision was based on research that demonstrated the efficacy of learning through active participation, interpretation, iteration, and reflection, especially when knowledge and skills are gained within an explicit scientific process context. In addition to significantly revising laboratory activities, we added new activities within the course framework that involved the use of two new, NSF-funded instruments, including a handheld X-ray fluorescence spectrometer (XRF) and an inductively coupled plasma-optical emissions spectrometer (ICP-OES), which we used to improve student understanding of qualitative and quantitative elemental analyses. Finally, we introduced the use of a new course reader that provided both background materials for each activity as well as a new focus on providing a scientific process context for students. To assess student learning, we used in-class observations, student-instructor discussions, pre- and postlearning questionnaires, prelaboratory quizzes, course activities completed during class time, modified postactivity reflection questions, practical examinations, and a final examination. We also included faculty, staff, and administrator perspectives to qualitatively assess the impact of course changes upon student learning. Our results imply that students achieved the primary learning goals we developed for this scientific literacy initiative, including: (1) improved understanding of the scientific process and the nature of science; (2) improved understanding of qualitative and quantitative elemental research methods; and (3) improved understanding of the applicability of scientific research to real-world problems. Importantly, our findings suggest that the integration of research-grade instrumentation into introductory coursework, in a scientific process context, is an effective way to promote scientific literacy as well as to provide opportunities for students to understand and apply the knowledge and skills necessary to perform scientific research. We believe that this example of a significant course redesign provides a model that can be transferred to other geosciences departments as well as to other scientific disciplines. (C) 2014 National Association of Geoscience Teachers. [DOI: 10.5408/13073.1]
\end{abstract}

Key words: scientific literacy, curriculum, laboratory course, instrumentation

\section{INTRODUCTION}

Introductory laboratory courses play an important role in geoscience teaching at most colleges and universities. Traditionally, these courses provide learning opportunities with some hands-on activity but are primarily focused on memorization of content without providing students the opportunity to participate directly in the practice of active science research (e.g., Latour, 1987). This represents a significant missed opportunity: since many of these students will not study science beyond these introductory courses, these laboratory activities may represent their only direct

Received 19 June 2013; revised 4 September 2013 and 23 December 2013; accepted 2 January 2014; published online 28 May 2014.

${ }^{1}$ Department of Geosciences, Trinity University, 1 Trinity Place, San Antonio, Texas 78212, USA

${ }^{2}$ Department of Chemistry, Trinity University, 1 Trinity Place, San Antonio, Texas 78212, USA

${ }^{3}$ Halx Consulting Group, 230 Dwyer Avenue, Unit 601, San Antonio, Texas 78204, USA

a Author to whom correspondence should be addressed. Electronic mail: bsurples@trinity.edu. Tel.: 210-999-7110. Fax: 210-999-7090 experiences with a scientist (the instructor). We believe that the introductory science laboratory is the ideal time to engage students with focused, hands-on, scientific investigation and discovery that will encourage some to pursue scientific research as a career and provide others with an authentic foundation for life-long scientific literacy.

The advantages of hands-on or project-based learning are well supported in the literature (e.g., Blosser, 1983; Baird, 1990; Bybee, 2000), and Nelson et al. (2010) found that students enrolled in university-level geoscience laboratory sections performed significantly better in an associated lecture course than their colleagues who were enrolled in the lecture course alone. Additionally, Richter-Egger et al. (2010) found improved student attitudes about science as well as improved learning related to the integration of instrument-based research into introductory science laboratories. Finally, Nakhleh and Krajcik $(1993,1994)$ found a positive correlation between the use of instrumentation and student understanding of specific chemical phenomena.

While the literature suggests a clear learning advantage is gained with hands-on laboratory activities, even when students collect qualitative and quantitative data and 
perform basic interpretations of those data in laboratory courses, they do not necessarily recognize this as participation in the scientific research process (e.g., Ryder et al., 1999; Schwartz et al., 2004). Introducing the use of new instrument-based activities into the laboratory curriculum certainly yields a positive impact on student learning and attitudes about science, but in order for students to achieve a much fuller understanding of the value of the scientific process and the nature of science research, it is also necessary to make their participation in the scientific processes explicit (e.g., Lederman, 2007) and permit them time to reflect on that participation (e.g., Schwartz et al., 2004; Carpi and Egger, 2010).

With these notions in mind, and supported by a National Science Foundation grant (award \#0942940), the geology and chemistry departments at Trinity University collaboratively developed a new scientific literacy initiative. This project began with the integration of research-grade instrumentation into existing introductory geoscience laboratory activities, while at the same time providing students a significantly revised curricular framework to explicitly emphasize many components of the scientific process and the nature of science, more generally. In this paper, we report on the development and implementation of course materials and curriculum associated with this initiative, student engagement before and after implementation, and our assessment of ultimate learning outcomes. The findings of this study support a new curriculum model that should improve students' overall scientific literacy and positively impact overarching departmental and institutional goals.

\section{WHAT IS SCIENTIFIC LITERACY?}

Although the term "scientific literacy" is not well defined in the literature (Deng et al., 2011, and references therein), Durant (1993) claimed that at its simplest, scientific literacy is "what the general public ought to know about science," (p. 129) while Jenkins (1994) more closely defined scientific literacy as implying "an appreciation of the nature, aims, and general limitations of science, coupled with some understanding of the more important scientific ideas" (p. 5345; see also Laugksch, 2000). Alternatively, the American Association for the Advancement of Science defined a scientifically literate person as someone who is familiar with the natural world, understands key concepts and principles of science, has the capacity for scientific reasoning, and is able to use scientific knowledge for personal and social purposes (AAAS Project 2061 et al., 1994; Jurecki and Wander, 2012). More relevant to introductory geoscience courses, the Earth Science community recently produced four major scientific literacy documents (Atmospheric Science Literacy Framework, 2007; U.S. Climate Change Science Program, 2009; Earth Science Literacy Initiative, 2010; Wysession et al., 2012; Ocean Literacy Framework, 2013) that provide summaries of "big ideas" that can be utilized by instructors at all levels to more effectively teach scientific literacy.

No matter the definition or framework for scientific literacy, an understanding of the scientific process is considered a vital component of scientific literacy (e.g., Millar and Osborne, 1998; Abd-El-Khalick and Lederman, 2000; Lederman, 2007; Deng et al., 2011), and Driver et al. (1996) stressed the personal and societal benefits of producing students who have sophisticated views of the nature of science. Importantly, Miller (2010a, 2010b, 2012) has clearly shown that exposure to college science courses is a strong predictor of civic scientific literacy in adults of all ages, so it is likely that all students who complete an introductory geoscience course will become more scientifically literate, regardless of pedagogy. However, since a student's ideas about the nature of science are constructed largely from his or her experiences in science classrooms and laboratories, and/or within other appropriate teaching contexts, students' views of science can be significantly developed and broadened (e.g., Ryder et al., 1999; Van Eijck et al., 2008) in well-designed college science laboratory courses.

\section{The Scientific Process and the Nature of Science}

Broadly held student misconceptions about the nature of science (e.g., McComas, 1998) provide additional challenges to our effort. Students commonly enter an introductory geoscience classroom with many misconceptions (best summarized in McComas, 1998), which include the ideas that the scientific process consists of a set of tasks that is prescribed and linear and is the same for all scientists (i.e., the scientific method), cannot involve creativity or innovation, begins with an educated guess about a given phenomenon (hypothesis formation), and must include experimentation to test that single hypothesis. The average student also thinks that once the hypothesis holds true for a few more experiments, the scientist has now developed a theory. Finally, if this theory can be proven true, it becomes a law, which is absolute. These inaccurate ideas have been introduced by instructors and reinforced in textbooks and classrooms at all levels of science education (e.g., McComas, 1998).

Although there is debate about what the "nature of science" should be (e.g., National Science Teachers Association, 1982; AAAS, 1993; NRC, 1996; Deng et al., 2011), there is some consensus about the nature of science among science educators (Deng et al., 2011), which is summarized by Lederman (2007). Lederman (2007) proposes that scientific knowledge: (1) is subject to change; (2) is based on or derived from observations of the natural world; (3) is subjective; (4) involves human imagination, inference, and creativity; and (5) is socially and culturally embedded. Further, Lederman (2007) includes the definitions of and relations between theories and laws as well as understanding the difference between observations and inferences.

Leach (2002) emphasized five broad areas that affect students' images of the nature of science that are specific to the laboratory setting, including: (1) the nature of data and measurement in empirical work; (2) the nature of investigation in science; (3) the nature of theory in science; (4) the nature of explanation in science; and (5) the nature of reliable public scientific knowledge. Building on the work of Leach (2002), Lederman (2007), and others, Carpi and Egger (2010) developed a well-documented and detailed compilation of learning modules that address the question, "What is science and how does it work?" that is consistent with and builds on the findings of Lederman (2007). Carpi and Egger's (2010) scientific process model includes most of the points proposed by Lederman (2007), and their "Nature of Science" graphic (Fig. 1) provides a succinct visual flow chart that can be used not only to teach students about the 
The Nature of Science
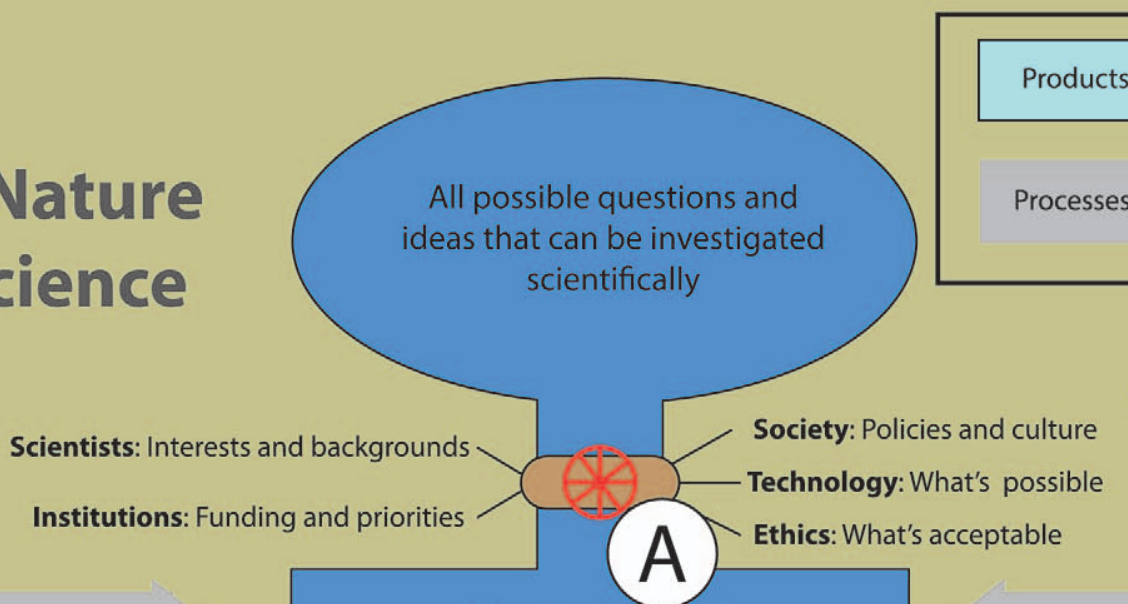

Products

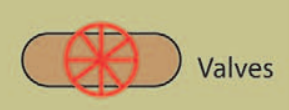

All of these things act as valves on the flow from all possible questions, influencing the science that gets done at any given time.

Questions that get

investigated scientifically

\section{The Practice of Science}

\section{Feedback into \\ further research}

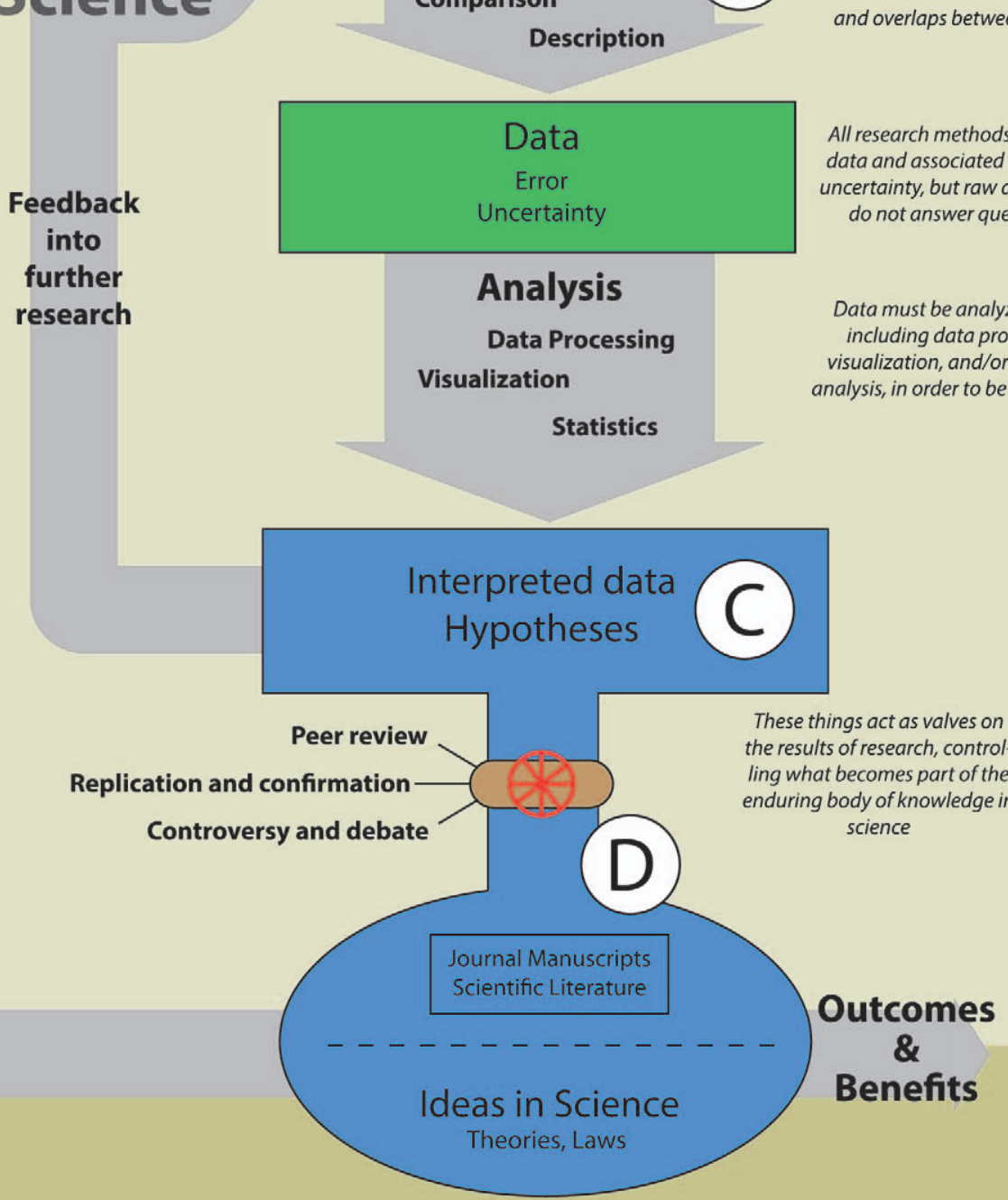

There are many research methods that can be used in scientific investigations, and there are links and feedbacks and overlaps between them.

All research methods produce data and associated error and certainty, but raw data alone do not answer questions.

Data must be analyzed, often including data processing. visualization, and/or statistical Visualization Statistics 
complexities of science in the real world, but also about the excitement and creativity that are part of every scientific endeavor.

\section{TEACHING SCIENTIFIC LITERACY}

Instructors contextualize learning opportunities related to the scientific process in a variety of ways (Guerra-Ramos et al., 2010), and the efficacy of that learning is affected, in part, by pedagogic context (e.g., Ryder et al., 1999; Schwartz et al., 2004; Van Eijck et al., 2008). To achieve science literacy at the $\mathrm{K}-12$ level, there has been emphasis on learning science by doing science for nearly five decades (e.g., Gagne, 1963; AAAS CSE and Gagne, 1965; O'Neill and Polman, 2004), and Tobin (1990) supports this view, suggesting that students construct their understanding by active participation, interpretation, and iteration. Notwithstanding the efforts of educational institutions at all levels to use these techniques, studies indicate that the average American remains far from scientifically literate (e.g., Culliton, 1989; Alters and Nelson, 2002; Keeter et al., 2007; Miller, 2012), suggesting that simply participating in the scientific process does not promote scientific literacy.

Although some researchers suggest that overall learning is more effective when knowledge is gained in the context of scientific processes (Cashin and Downey, 1995; Smart and Ethington, 1995), Lederman (2007) suggests that learning goals related to scientific literacy are better achieved by making students' participation in the scientific process explicit. Further, Schwartz et al. (2004) indicate that teaching in the context of hands-on activities requires both explicit discussions and opportunities for individual reflection in order for students to construct a more complete understanding of the process of science. In addition, Jurecki and Wander (2012) point out that critical thinking is a key, although implicit, component of scientific literacy that is very rarely emphasized within scientific curricula, especially at the introductory level. This finding is supported by Deng et al. (2011), who point out the importance of argumentation, which involves making and justifying claims and conclusions (Driver et al., 2000; Zohar and Nemet, 2002; Sampson and Clark, 2009).

\section{A NEW SCIENTIFIC LITERACY INITIATIVE}

Supported by a National Science Foundation grant (award \#0942940) awarded in 2010, faculty within the departments of geosciences and chemistry at Trinity University collaboratively developed activities related to new research-grade instruments and integrated those activities into existing course curricula. The new instruments funded by the grant included a handheld X-ray fluorescence spectrometer (XRF) and an inductively coupled plasmaoptical emission spectrometer (ICP-OES). The versatility and portability of handheld XRF technology permit real-time elemental analysis in the laboratory or in the field. The handheld XRF unit, approximately the size of a hair dryer, produces $X$-rays that are directed at the sample. When these $X$-rays strike atoms within the sample, many atoms become ionized and re-emit $X$-rays (secondary $X$-rays) with energies that are characteristic of elements present in that sample. The secondary $X$-rays are detected by the handheld XRF, permitting identification of those elements. A handheld XRF can detect the presence of elements as light as magnesium, with many elements detectable at the ppm level. ICP-OES is used primarily for the analysis of metals in a liquid. The sample is injected into an inductively coupled plasma torch as a nebulized spray in order to excite ions and atoms present in that sample. The excited species then emit electromagnetic radiation characteristic of each species, and the intensity of each signal emitted from the sample is indicative of each species' concentration. The ICP-OES method provides quantitative data, with detection limits in the low ppm range. Previous researchers have established a link between the use of instrumentation and student learning about science (Nakhleh and Krajcik, 1993, 1994; Richter-Egger et al., 2010), and these new tools provide opportunities for us to better involve students in elemental analysis of a range of materials, to delve deeply into how the instruments work, how these tools obtain elemental information, and how scientists (the students) use this information in an explicit scientific process context.

Our overarching objectives for this initiative included: (1) improving student understanding of the scientific process and the nature of science; (2) improving student understanding of quantitative and qualitative elemental analyses; and (3) improving student understanding of the applicability of science to real-world problems. To achieve these objectives, a significant component of this curricular initiative was to provide an explicit, scientific process-based framework for learning opportunities in grant-related science courses, while also providing students opportunity to think critically about the results obtained as a result of these processes and to reflect on their participation in science. Although both departments have been involved in a range of curricular initiatives related to this grant, here we focus on the results of our efforts to revise activities within an introductory geoscience laboratory course with the goal of achieving the objectives listed here.

\section{STUDY POPULATION AND SETTING Trinity University and General Education Requirements}

Trinity University is a small (approximately 2,500 students), private, primarily undergraduate, liberal arts college with a predominantly residential student population and a semester-based curriculum. Students are required to complete general education requirements across a range of "understandings," including an "understanding natural science and technology" requirement. This requirement has the rationale:

This understanding addresses the need of all students to understand the implications and benefits of science and technology, along with an appreciation of the potential and the limits of science and technology to address societal needs. The goal of courses in this category is to promote greater literacy in science and technology by teaching students to understand: a) the fundamental nature of science; $b$ ) the methods and results of the natural sciences; $c)$ the methodologies of science and technology; and d) the relationship between science and technology. (Trinity University, 2013, p. 31) 

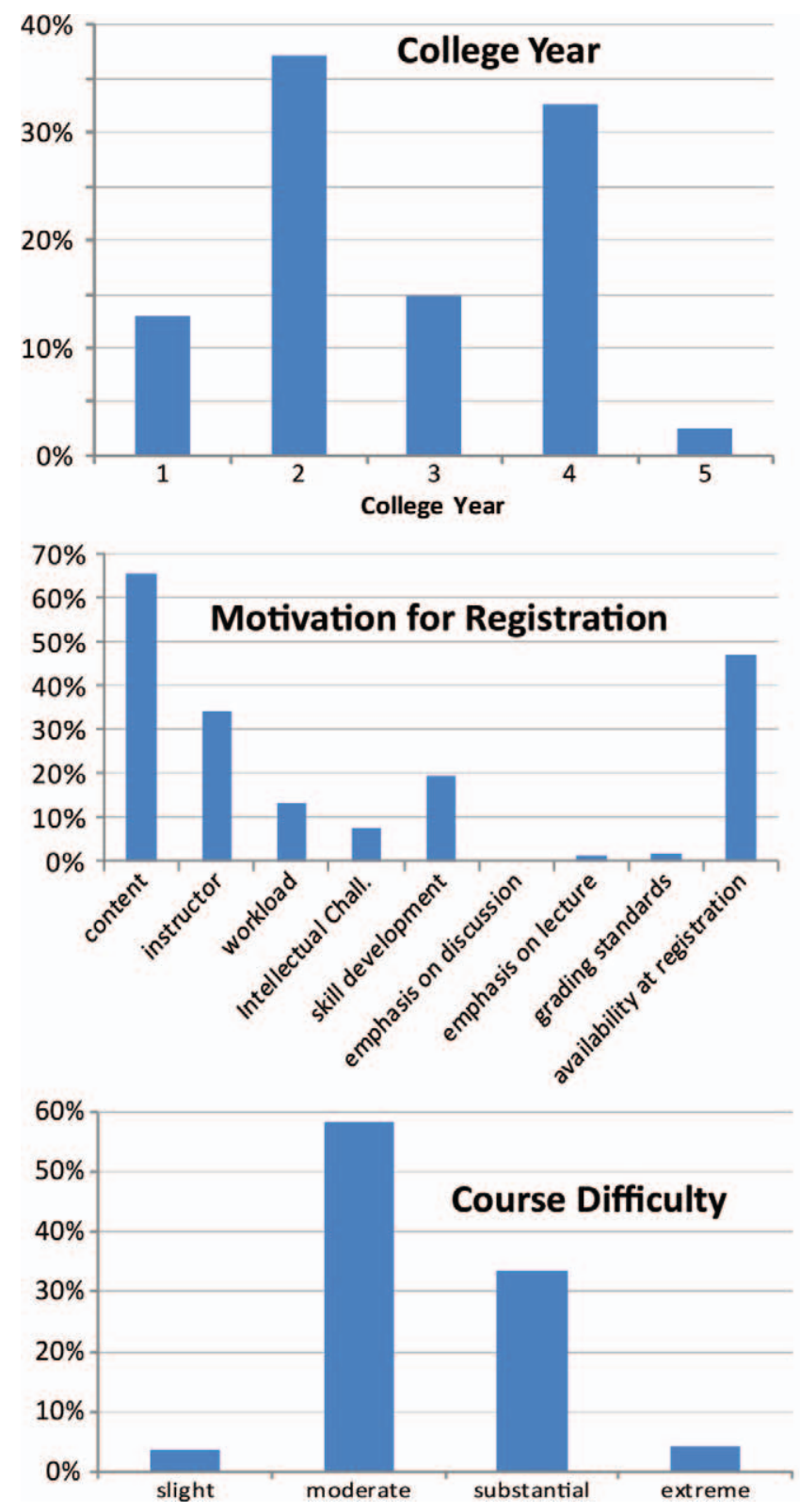
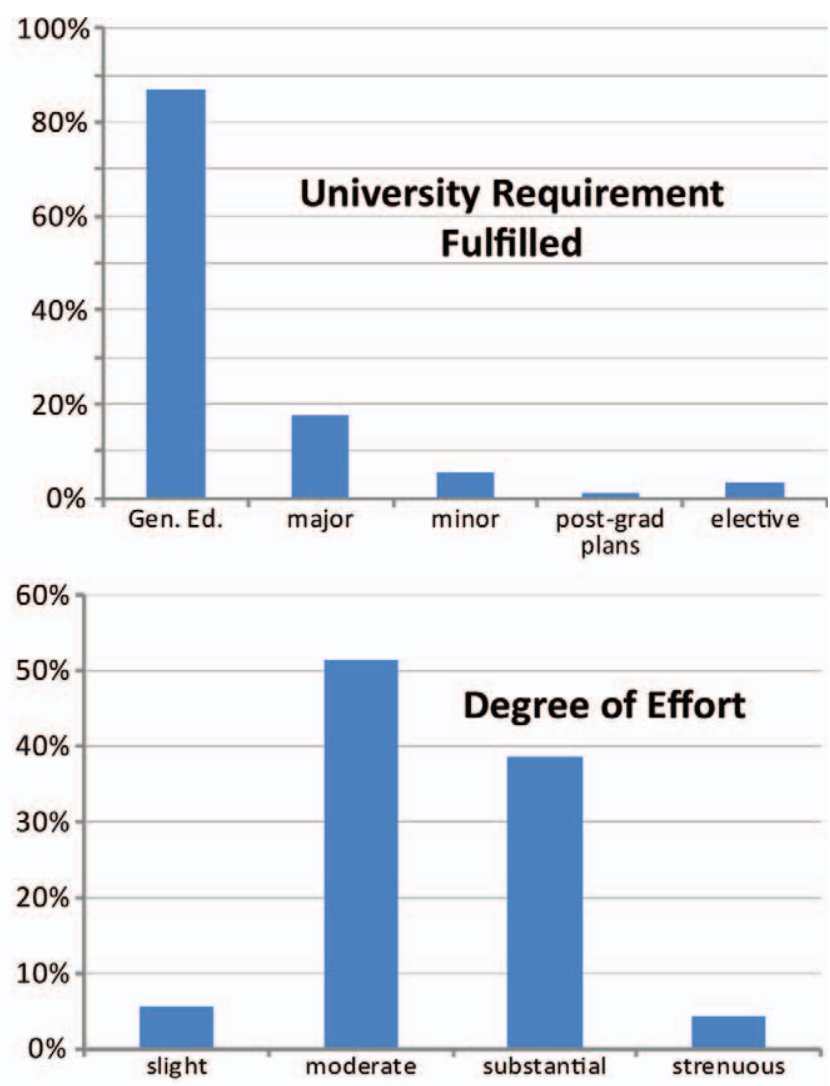

FIGURE 2: Study population demographic information for physical geology laboratory course at Trinity University.

Although not stated explicitly, this understanding emphasizes the importance of scientific literacy for all graduates. In addition to standard coursework in the natural sciences, students are also required to complete a laboratory course such as the physical geology laboratory, the course that is the focus of our study.

\section{Introductory Geoscience Laboratories and Lectures}

At Trinity University, students have two primary options for fulfilling their general education laboratory requirement in geoscience. They may enroll in a studio-based physical geology course that integrates lecture, discussion, group work, and laboratory activities, or they may enroll in a standalone physical geology laboratory course, which requires that students take a separate environmental geology course as a pre- or corequisite. Any student who wishes to enroll in any of the core courses in the geoscience curriculum must complete either the integrated lecture-laboratory course or both the environmental geology lecture course and the physical geology laboratory course.

In total, 170 undergraduate students $(N=170)$ enrolled in eight sections of the physical geology laboratory course, with two sections offered each semester, including fall 2010, spring 2011, fall 2011, spring 2012, and fall 2012. All sections were taught by Trinity University faculty and met once per week for $3 \mathrm{~h}$ throughout a $15 \mathrm{wk}$ semester. The mean student age at the time of enrollment was $20.6 \mathrm{y}$, with a standard deviation (SD) of $1.6 \mathrm{y}$, and $57 \%$ of students were female. The sample population consisted of $90.1 \%$ Caucasian, $12.1 \%$ Hispanic, 4.3\% nonresident alien/foreign, 2.1\% black, and 1.4\% native American, with 3.6\% nonrespondent. Students' class varied significantly (Fig. 2), with $13.0 \%$ firstyear students, 37.0\% second-year students, $14.8 \%$ third-year students, $32.6 \%$ fourth-year students, and 2.5\% fifth-year 
TABLE I: Summary of curricular changes in physical geology laboratory course.

\begin{tabular}{|c|c|}
\hline Change & Rationale \\
\hline $\begin{array}{l}\text { Modified oral and written introductions } \\
\text { to all laboratory course activities }\end{array}$ & $\begin{array}{l}\text { To provide better context for each activity within the course and within the scientific } \\
\text { process framework. }\end{array}$ \\
\hline $\begin{array}{l}\text { New reflection questions on many } \\
\text { activities }\end{array}$ & $\begin{array}{l}\text { To provide students opportunity to reflect on the ways in which activities relate to the } \\
\text { scientific process. }\end{array}$ \\
\hline $\begin{array}{l}\text { Revised igneous, metamorphic, and } \\
\text { sedimentary rock laboratory activities }\end{array}$ & $\begin{array}{l}\text { To provide students a better framework for descriptive and comparative research. To } \\
\text { provide students a more realistic scientific experience, especially in regard to } \\
\text { interpretation of the environments of rock formation. }\end{array}$ \\
\hline Added course reader & $\begin{array}{l}\text { To provide a single source for all laboratory support materials that is organized within a } \\
\text { scientific process framework. }\end{array}$ \\
\hline New prelaboratory quizzes & $\begin{array}{l}\text { To provide incentive to complete prelaboratory readings prior to activities and to increase } \\
\text { the time available for faculty-student interaction when students are actively involved in } \\
\text { research. }\end{array}$ \\
\hline New scientific method activity & $\begin{array}{l}\text { To spur students to think carefully about their own conceptions of the scientific method, } \\
\text { prior to any class discussion of the scientific process. To provide a model and a resource } \\
\text { for the scientific process }{ }^{1} \text { as practiced in the real world. }\end{array}$ \\
\hline New XRF elemental analysis activity & $\begin{array}{l}\text { To introduce students to atomic structure, the power of the periodic table, and X-ray } \\
\text { instrumentation and elemental analysis. To demonstrate the importance of similar tools to } \\
\text { the advancement of knowledge within the scientific process. }\end{array}$ \\
\hline $\begin{array}{l}\text { New "real-world" investigation of } \\
\text { campus soils, bedrock, and human } \\
\text { influence }\end{array}$ & $\begin{array}{l}\text { To further demonstrate the power of elemental analysis in answering research questions } \\
\text { that can be applied to real-world challenges. To involve students in research that involves } \\
\text { research question construction, hypothesis formation, hypothesis testing, and hypothesis } \\
\text { modification/rejection. }\end{array}$ \\
\hline
\end{tabular}

${ }^{1}$ Primary resource: Carpi and Egger (2010).

students. The mean grade point average of students upon entering the course was 3.26 (on a 4 point scale), with a SD of 0.45 . On course evaluations, students reported that $87.1 \%$ took the course to fulfill general education requirements, $17.8 \%$ to fulfill requirements for their major, $5.5 \%$ to fulfill requirements for their minor, $1.2 \%$ to prepare them for postgraduation plans, and $3.1 \%$ to fulfill elective requirements. Students' reasons for registering in the course most commonly included course content, the instructor, and availability at registration, and $91.9 \%$ of students perceived the course as moderately to substantially difficult, with 3.7\% considering the course slightly difficult and $4.4 \%$ considering the course extremely difficult. The level of effort expended, according to students, was primarily moderate to substantial, at $90.0 \%$, with $5.6 \%$ considering their effort slight and $4.4 \%$ considering their effort extreme (Fig. 2).

\section{METHODS: CURRICULAR REVISION}

Geosciences faculty developed a revised framework for the department's introductory-level physical geology laboratory beginning in the summer of 2010. Starting with the student learning goals for the NSF-funded initiative, we worked to integrate ideas and activities associated with scientific literacy throughout both existing and new laboratory activities to achieve those goals. Coupled with a new focus on the scientific process, we also worked to integrate use of the two new research-grade instruments (the handheld XRF and ICP-OES) into the laboratory's curriculum. All changes were instituted during the 2010-2011 academic year.

Prior to the fall of 2010, physical geology laboratory was taught as a series of activities that were designed to introduce students to laboratory methods and to provide students opportunities to improve their knowledge of the solid Earth and Earth processes. At the beginning of every course meeting, faculty would briefly aid students in making important connections between earlier activities and the student activity to be performed that day. Faculty supplied materials specific to the day's activity, which included both guidelines for the activity itself and supporting documents to aid them in completing the activity (e.g., igneous rock classification chart and definitions of textural and compositional terms). We recognized that students who completed the course had achieved the primary learning goals at some level, but it was not clear to faculty that students understood how these activities related to the process of science, especially the way in which their participation in these activities could be related to the work that scientists undertake or the manner in which science impacts society. In addition, none of these activities involved the use of qualitative or quantitative elemental analysis to answer research questions, something that is vitally important to research across all scientific disciplines.

In order to achieve initiative objectives and to improve overall student learning of the fundamental skills and concepts of physical geology, faculty instituted a number of important changes to the curricular structure of the physical geology laboratory (Table I). These changes were integrated into the course at a number of different levels, from relatively simple, minor modifications to the addition of a course reader and new activities.

\section{Providing New Context: A Visual Model for the Nature of Science}

To combat many of the flawed conceptions about the nature of science and the scientific process, we decided to use a visual model that reveals the robust, dynamic, and 
TABLE IIA: Chart to be completed by student for igneous rocks activity (prior to revision).

\begin{tabular}{|l|l|l|l|c|}
\hline Sample & Texture & Minerals Identified & Overall Composition & Rock Name \\
\hline & & & & \\
\hline
\end{tabular}

diverse nature of science as practiced in the real world. We built much of our framework around Carpi and Egger's (2010) scientific process model, focusing especially on the "Nature of Science" graphic (Fig. 1), which provides students with a succinct visual flow chart that can be used not only to teach students about the complexities of science in the real world, but also about the excitement and creativity that are part of every scientific endeavor.

Although we guided class discussion about many parts of the scientific process and the nature of science at many times throughout the course, we focused especially on several components of the scientific process represented in Fig. 1. These included the "valve" that constrains research questions (A in Fig. 1), research methods used by scientists (B in Fig. 1), the ways in which analysis of data can be used to develop interpretations and testable hypotheses ( $\mathrm{C}$ in Fig. 1 ), and the "valve" that constrains how scientists disseminate ideas that result from their research (D in Fig. 1). We also discussed the importance of theories and laws in science, thinking especially about how these terms are understood by the general public relative to how these terms are actually used by scientists. We purposefully integrated many of the modules from Carpi and Egger's (2010) work into course materials, which ranged from a new laboratory reader to class discussions of how individual activities might fit within a scientific process framework.

\section{Revision of Existing Laboratory Activities}

By modifying both the oral and printed introduction to laboratory activities, we provided students with a more succinct picture of how each activity fit within both earlier and later physical geology concepts, as well as, in many cases, how a given activity might fit within the scientific process (Fig. 1). We also added reflection questions on many activities that provided students with an opportunity to reflect and demonstrate their overall understanding of both how that activity fit within the scientific process framework and how material learned could be related to knowledge gained in past activities. Finally, we significantly revised igneous, sedimentary, and metamorphic rock activities to better reflect the way that a geologist would observe and interpret the rocks, guiding students in a way that emphasized the importance of descriptive and comparative research methods (B in Fig. 1) to the overall understanding of geologic processes.

TABLE IIB: Revised chart format for igneous rocks activity.

\begin{tabular}{|l|}
\hline Rock Sample \#3 \\
\hline Texture: \\
\hline $\begin{array}{l}\text { Mineral observations (box compressed due to space } \\
\text { constraints): }\end{array}$ \\
\hline Overall composition: \\
\hline Interpretation (box compressed due to space constraints): \\
\hline Possible plate tectonic environment: \\
\hline
\end{tabular}

For example, when students begin working with igneous rocks, we introduce them to the primary criteria that are the basis for the igneous rock classification system. Following an instructor-led discussion of the importance of texture and composition in the interpretation of igneous rocks, students begin observing and describing a set of samples. Prior to the revision of this activity, students were given the classification charts that would aid them in naming the rock based on texture and composition (e.g., porphyritic basalt), and students were supplied with a standard test kit, (hand lens, nail, glass, and streak plate), a binocular stereoscope to view hand samples, and a visual percent chart to estimate mineral percentages in rock samples. With these tools and support materials, students examined hand samples and completed a chart with the columns shown in Table IIA.

Based on laboratory experiences, faculty felt this was a flawed approach. Instead of using careful observation and description to classify igneous rocks, students would commonly pick up a sample, guess what rock it was, and use the classification chart to fill in the minerals that were expected to be present. While the best students spent time identifying visible minerals in the rock, with 14 total samples to describe and classify, even those students focused more on finishing the laboratory exercise than on understanding the importance of the rock classification system or using their descriptions to better understand the environment of formation for a given rock. Thus, we revised the activity to emphasize the importance of careful observation and to engage students in the thought processes that enable geologists to interpret environments of rock formation.

We reduced the total samples to be described from 14 to five, and we changed the format of the laboratory handout to emphasize those items we felt to be most important (Table IIB). The new chart format included a significant amount of space for students to describe visible minerals and/or groundmass characteristics, including the average measured size and range in size of mineral crystals, the color of the mineral in the sample, and the approximate percentage of the mineral present. The chart also included a new "Interpretation" box, where students were required to interpret the environment of formation for each rock, using the evidence that they presented in their "Texture" (i.e., phaneritic, aphanitic, or porphyritic aphanitic), "Mineral observations," and "Overall composition" (i.e., mafic, intermediate, or felsic) boxes. This interpretation included the location(s) where these rocks most likely formed (e.g., magma chamber), the magma composition present, and the rates of cooling expected to generate a rock with the composition and appearance of their hand sample. Finally, students were required to include at least one tectonic environment where such a rock could form. Importantly, we did not supply students with either a classification chart or an opportunity to name the rock (compare Figs. 2A and 2B). We included discussion and supporting materials about the classification system and rock-naming conventions as part of the next week's activity. We also revised other activities that involved hand samples, especially those focused on sedi- 
mentary and metamorphic rocks, for similar reasons and in a similar way.

\section{New Course Reader}

Prior to this initiative, geoscience faculty distributed supporting materials prior to each activity, discussing the importance of those materials to the concepts and skills introduced that day. While the support materials were important references for students working on laboratoryrelated materials, the relationships between supplemental materials either to each other or to the overall course were not explicit. To improve both the quality of the supplemental materials and the relationship between the materials and overall course goals, we combined all supplemental materials into a single course reader, while also providing additional text to introduce the reader to materials and to provide explicit reminders of the research methods being used in completing each activity. We also added a significant introduction to the reader, focusing on the scientific process, using Carpi and Egger (2010) as a primary resource. Near the end of the reader, we included all classification diagrams and other materials that students would use frequently (e.g., periodic table, geologic timescale, a graphic to aid in percent estimation).

With the introduction of a new course reader, we added a new set of expectations for student preparation. Prior to each laboratory, students were expected to read the section of the course reader related to activities performed that day. To provide incentive for preparation, we distributed prelaboratory quizzes at the beginning of each meeting. We hoped these quizzes would also provide valuable feedback about which topics were most challenging for students.

\section{New Activities}

We were limited in the number and type of activities that we could add to the physical geology laboratory curriculum. Therefore, most of our new activities were relatively short, focused activities designed to engage students in both the content and skills necessary to achieve learning goals.

We developed a simple activity to engage student in active reflection about their conceptions of the scientific method/process. This activity was designed to spur students to think about how their own ideas about scientists and the nature of science meshed with the way that science is practiced in the real world. Each student worked with a partner to develop a flow chart that was a graphical representation of their views about science. This exercise was used as a springboard for a classwide discussion of the scientific process and a general introduction to the course.

We added a new activity to introduce the handheld XRF and elemental analysis to students. The activity included an introduction to the physics behind elemental analysis and a discussion about atomic structure and the periodic table. This elemental analysis activity immediately followed an activity focused on the exploration of minerals and mineral properties, so the first part of the exploration included analysis of powdered mineral samples, using two samples of the same mineral with different colors (e.g., Ca-rich plagioclase feldspar versus $\mathrm{Na}$-rich plagioclase feldspar). The activity was designed to encourage students' recognition of the power of research-grade instruments to reveal detailed elemental information. In addition, another learning goal was for students to learn that color alone was not a good diagnostic for mineral identification; variations in mineral color are controlled by slight changes in the elemental composition of minerals. Finally, we guided discussion to include the definition of a mineral, thinking carefully about how elements substitute into positions within a mineral's crystal structure.

Finally, we included a multistep research project that involved the use of both the handheld XRF and the ICPOES. This research project was developed as an analysis of bedrock and soils on the Trinity University campus, focusing especially on the composition of soil horizons relative to both the regolith and bedrock immediately beneath much of the campus as well as to human activities. The project steps, spread throughout the course as short exercises, included: (1) a guided research question development exercise, based on detailed student observations of the sampling locations and background information about campus construction provided by instructors; (2) XRF analysis of the soils and bedrock samples to provide information about the relative elemental concentrations in the soils and bedrock; (3) a hypothesis formation exercise, based on the originally posed research questions and the elemental data collected by XRF; (4) ICP-OES analysis of the same samples to provide quantitative data about elements chosen by students in the third step of the project; and (5) a closing exercise, where students use all available data, their original research questions, and their hypotheses to develop new hypotheses that best explain the data. This final project also includes a section that pushes students to think carefully about what other information would help them in their investigation of soils on campus.

\section{METHODS: ASSESSMENT FRAMEWORK}

Students' ideas about the nature of science are so dynamic and varied that reliable, valid assessment of student learning in topics related to the nature of science is difficult (Lederman et al., 1998). In addition, students' ideas about the nature of science might appear to be different depending on the questions asked, the assessment method used, and when an assessment tool is used, especially considering the blend of experiences through which students construct their ideas (Leach et al., 2000; Roth and Lee, 2007; Van Eijck et al., 2008). In order to most effectively measure student learning related to our overarching initiative objectives, we designed a wide range of both quantitative and qualitative assessment tools that we administered at different times throughout the course (Table III) and that were analyzed by multiple observers. For all qualitative assessment tools, we utilized standard qualitative content analysis, which consists of "identifying, coding, categorizing, and labeling primary patterns" (Patton, 2002) in our analysis of that data. Our assessment framework thus utilizes both methods and analyst triangulation, as defined by Patton (2002), to evaluate the consistency of our findings. With this design, we attempted to avoid the bias that is common in singlemethod, single-observer, and/or single theory studies (Denzin, 1989).

The assessment tools were structured to provide frequent feedback to both students and instructor, which could then be used to both inform activities performed later in the course and in subsequent offerings of the physical 
TABLE III: Chronological list of assessment tools and response types for physical geology laboratory.

\begin{tabular}{|c|c|c|c|}
\hline Week & Assessment Tool & Response Type & $\begin{array}{l}\text { Objective(s) } \\
\text { Assessed }^{1}\end{array}$ \\
\hline 1 & Prelearning questionnaire ${ }^{2}$ & Likert scale questions; free response & $1,2,3$ \\
\hline 1 & Scientific method construction $^{2}$ & Free response, including flow chart construction & 1 \\
\hline 3 & Trinity rock/soil project: introduction & Free response (research question formulation) & $1,2,3$ \\
\hline 4 & $\begin{array}{l}\text { Trinity rock/soil project: XRF analysis of } \\
\text { minerals, rock, and soil samples }\end{array}$ & Free response (laboratory activity and follow-up summary) & $1,2,3$ \\
\hline 5 & Quiz (elemental analysis) & Multiple-choice and free response & 2 \\
\hline 6 & Practical exam I & $\begin{array}{l}\text { Free response (observation and interpretation of rock } \\
\text { samples) }\end{array}$ & $1,2,3$ \\
\hline 7 & $\begin{array}{l}\text { Rock interpretation and the practice of } \\
\text { science in geology }\end{array}$ & $\begin{array}{l}\text { Free response (self-reflection on students' use of the } \\
\text { scientific process in completing the laboratory activity) }\end{array}$ & 1,3 \\
\hline 9 & Trinity rock/soil project: ICP-OES analysis & Free response (laboratory activity) & $1,2,3$ \\
\hline 11 & Quiz (scientific process) ${ }^{3}$ & Multiple-choice and free response & 1 \\
\hline 13 & Practical exam $\mathrm{II}^{3}$ & $\begin{array}{l}\text { Free response (both rock interpretation and scientific } \\
\text { process) }\end{array}$ & 1,3 \\
\hline 15 & Postlearning questionnaire ${ }^{3}$ & Likert scale questions; free response & $1,2,3$ \\
\hline N/A & NSF summative report ${ }^{3}$ & $\begin{array}{l}\text { External evaluator used all available data (see above) in } \\
\text { addition to other methods of data collection (see text for } \\
\text { discussion) }\end{array}$ & $1,2,3$ \\
\hline
\end{tabular}

${ }^{1}$ Objectives listed in "A New Scientific Literacy Initiative" section.

${ }^{2}$ Prelearning activities addressed in text discussion.

${ }^{3}$ Postlearning activities addressed in text discussion.

geology laboratory. Importantly, we included assessment of student learning and overall project efficacy by an external evaluator (Table III). Many assessment tools, including student questionnaires and faculty interviews, were designed to measure the same constructs in both pre- and postlearning applications. However, in several cases, time constraints prevented us from designing a prelearning assessment tool that could be directly tied to a postlearning assessment tool.

Questionnaires (Table III) included both Likert scale statements as well as open-ended free-response questions to elicit deeper information about student learning. We included both pre- and postlearning questionnaires, which are particularly effective at assessing the attainment of learning goals (Libarkin, 2001). In addition to assessing the attainment of initiative goals, the prelearning questionnaire permitted us to tailor students' learning opportunities to best match existing student attitudes and conceptions (Libarkin, 2001) and maximize the efficacy of student learning (Hofstein and Lunetta, 2003). We also used assessment questions that target student attitudes toward science and the scientific method (Aikenhead and Ryan, 1992; Bradford et al., 1995; Libarkin, 2001), and we utilized Carpi and Egger's (2010) discussion of data analysis and interpretation to help mold the Likert scale statements.

We embedded assessment tools in laboratory activities, quizzes, and practical exams throughout the term (Table III). Two new quizzes and revised practical exams (Table III) were designed to assess student learning goals. With this overall structure, we provided students frequent opportunities for both active participation in scientific investigations and interpretation within an explicit scientific process framework. This assessment plan also provided us with frequent feedback about student learning, so that we could tailor subsequent activities to mitigate problems that we observed in either the activities themselves or in the context that we provided for those activities. It is important to note that instructors commonly provided oral feedback during class discussions that took many forms, including, but not limited to: correcting misconceptions as students expressed them; providing additional context for a discussion topic (if deemed necessary and relevant); pointing out connections between a given activity and prior activities; and pointing out the relation of the day's activities to the scientific process. We provide all course materials related to this assessment effort in the Supplemental Materials (available at: http://dx.doi.org/ 10.5408/13-073s1 and http://dx.doi.org/10.5408/13-073s2).

\section{External Evaluation Methods}

Our external evaluator (coauthor M. Halx) provided both quantitative and qualitative evaluation of grant-related activities (Table III). The quantitative methods consisted primarily of Likert scale questions on pre- and postlearning questionnaires, as described earlier. The qualitative methods included constant comparative coding and analysis of both the student text responses to open-ended questions on the pre-and postlearning questionnaires and of transcripts from faculty, administrator, and staff interviews. Although similar to standard comparative coding (discussed earlier herein), the constant comparative method includes the addition of a dynamic process in which the researcher constantly revisits and compares previously gathered data to determine if adjustments to the research process are necessary. This method encourages rigor and researcher accountability through open, axial, and selective coding (Strauss and Corbin, 1998). This three-tiered process requires multiple passes through the data to assure that data saturation has been achieved and that no themes have been overlooked. In addition, Halx tested the validity of his findings by verifying 
researcher interpretations with evaluation participants, a process also known as "member checking" (Patton, 2002). "Analytic memos" (Saldaña, 2009) were also maintained throughout the evaluation period. These "memos" are frequent notes of any analytic or methodological thought or research question recorded as those thoughts occur, which are later used to inform the analysis process (Saldaña, 2009). During the analysis process, no automated discourse analysis program was used. Instead, in vivo coding (Saldaña, 2009) was utilized. This coding is drawn from the participants' own words and avoids researcher-assigned labels (Saldaña, 2009). This method provides direct individual insights that are unaffected by coding processes. Separate in vivo code grouping schemes were developed for faculty, administrators, staff, and students in order to parallel the specific research pursuit for each participant pool. For the faculty, administrators, and staff participants, the coding scheme focused on the value of the new instruments and effectiveness of the curricular changes. For the student participants, the coding schemes focused on evidence of student learning and increased understanding. The response rate to the student questionnaires averaged approximately $90 \%$ for each semester measured $(N=170$ for the entire study). We summarize the external evaluator's summative evaluation in the following section.

\section{RESULTS: PRE- AND POSTLEARNING ASSESSMENT DATA}

Although we developed a detailed assessment framework with frequent feedback mechanisms for activities throughout physical geology laboratory, we here focus on the total change in student skills and knowledge, focusing especially on student assessment data from the beginning and the end of the course. For prelearning assessment, we focus on the prelearning questionnaire, the scientific method construction activity, and the Trinity rock/soil project introduction (Table III). For postlearning assessment, we focus on the postlearning questionnaire, the scientific process quiz, the second practical exam, and the last step in the Trinity rock/soil project ("Trinity rock/soil project: ICP-OES analysis" in Table III). For the class activities, we use both the questions/statements posed as well as excerpts from student responses (original student responses are included in the Supplemental Materials). Finally, we summarize the student learning section of the summative evaluation provided by the project's external evaluator.

\section{Prelearning Questionnaire}

Students responded to 4 Likert scale statements (Fig. 3), with a scale that included: strongly disagree (SD; 1 point); disagree (D; 2 points); neutral (3 points); agree (A; 4 points); and strongly agree (SA; 5 points). In responding to the statement, "I understand the scientific method," $85.6 \%$ of students selected agree or strongly agree, with a standard deviation of 0.71 from the average of 4.04 (Fig. 3; all prelearning responses in black). Students responses to the statement, "I know the basic structure of the atom," suggested slightly less student confidence in understanding, with an average of 3.79 and a standard deviation of 0.90 , but $74.3 \%$ of students did select agree or strongly agree (Fig. 3). For the statement, "I understand what an X-ray is," $62.8 \%$ of students selected agree or strongly agree, with an average of
3.51 and a standard deviation of 0.88 (Fig. 3), indicating still less confidence in their understanding of that concept, relative to the first two statements. Finally, the statement, "I understand the basic relationship between electron shells and energy," elicited only $38.5 \%$ agree or strongly agree responses, with an average of 3.10 and a relatively large standard deviation of 1.04 (Fig. 3). These data suggest that prior to taking the physical geology laboratory course students were most confident about their understanding of the scientific method, were less confident about their understanding of atomic structure or X-rays, and were the least confident about electron shell-energy relationships.

Students also responded to four other statements, with possible responses including agree, disagree, and cannot decide (Fig. 4). In addition, we provided students with the opportunity to explain why they chose the response that they did. Figure 4 includes bar graphs that display student responses (black bars = prelearning; gray bars = postlearning), and to the right of the graphs are selected student responses. In responding to the statement, "Good scientific data can only be interpreted in one way," $80 \%$ of students disagreed, with only 5.1\% agreeing with the statement. Also, $98.7 \%$ of students agreed with the statement, "Even when scientific investigations are done correctly, the information that scientists discover may change in the future." Students responding to the statement, "Scientific research must involve experimentation," selected agree $66.6 \%$ of the time, while $23.1 \%$ selected disagree, and $10.3 \%$ could not decide. Finally, $41.1 \%$ of students agreed with the statement, "If multiple hypotheses can explain the same set of observations, the simpler hypothesis is preferred by scientists," while $29.4 \%$ disagreed, and $29.5 \%$ could not decide. We also requested that students select all fields (e.g., biology, chemistry, geology) for which they thought X-ray fluorescence analysis could be applied to answer research questions (Fig. 4).

\section{Scientific Method Construction Activity (Prelearning)}

In order to assess student understanding of the scientific process, we requested that students respond to the following free response opportunity: Explain the scientific method, using a flow chart to aid in your explanation. Students worked with a partner to develop their explanation and flow chart. Student explanations of some parts of the scientific method were surprisingly consistent, with all student flow charts including hypothesis formulation, experimentation, and conclusions. Nearly all explanations included either a linear or a circular flow chart. Two samples of the circular models are included in Fig. 5, and four samples of the linear models are shown in Fig. 6 (raw scans of these diagrams are included in the Supplemental Materials).

These flow charts all start with an observation, a problem, or a question (Figs. 5 and 6). In two cases, (Figs. $5 \mathrm{~B}$ and $6 \mathrm{~A}$ ), students included research prior to hypothesis formulation. In all cases, students included hypothesis formulation and followed that step with experimentation (or hypothesis testing). With two exceptions (charts in Figs. 6C and 6D), students include data collection as a step that follows experimentation/hypothesis testing, and in these same scientific method models, students also include data analysis after data collection. In three of these four student flow charts (Figs. 5A, 5B, and 6A), data analysis was followed by a conclusion, but in the fourth of these flow charts (Fig. 


\begin{tabular}{|l|c|c|}
\hline I understand the scientific method. & Pre-Learning & Post-Learning \\
\hline Strongly agree (5) & $23.1 \%$ & $35.2 \%$ \\
\hline Agree (4) & $61.5 \%$ & $63.0 \%$ \\
\hline Neither agree nor disagree (3) & $11.5 \%$ & $1.9 \%$ \\
\hline Disagree (2) & $3.8 \%$ & $0.0 \%$ \\
\hline Strongly disagree (1) & $0.0 \%$ & $0.0 \%$ \\
\hline & Average = 4.04 & Average = 4.33 \\
\hline & SD = 0.71 & SD $=\mathbf{0 . 5 1}$ \\
\hline
\end{tabular}

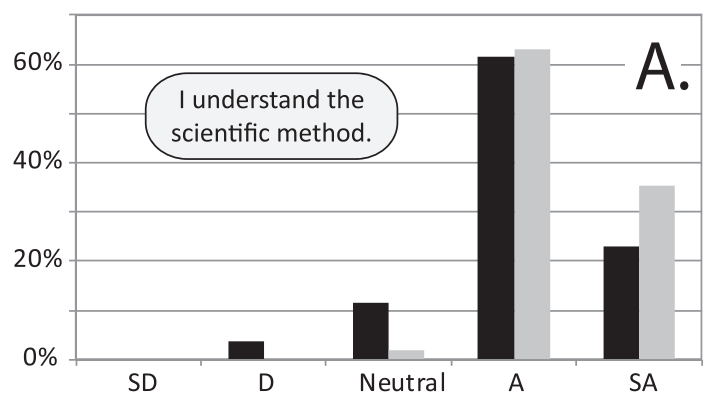

\begin{tabular}{|l|c|c|}
\hline I know the basic structure of the atom. & Pre-Learning & Post-Learning \\
\hline Strongly agree (5) & $17.9 \%$ & $29.6 \%$ \\
\hline Agree (4) & $56.4 \%$ & $54.7 \%$ \\
\hline Neither agree nor disagree (3) & $14.1 \%$ & $13.0 \%$ \\
\hline Disagree (2) & $10.3 \%$ & $0.0 \%$ \\
\hline Strongly disagree (1) & $1.3 \%$ & $0.0 \%$ \\
\hline & Average $=\mathbf{3 . 7 9}$ & Average $=\mathbf{4 . 1 7}$ \\
\hline & SD $=\mathbf{0 . 9 0}$ & SD $=\mathbf{0 . 6 4}$ \\
\hline
\end{tabular}

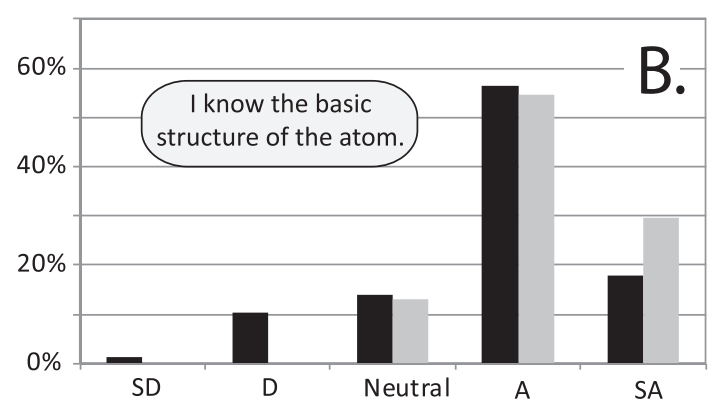

\begin{tabular}{|l|c|c|}
\hline I understand what an $\mathbf{x}$-ray is. & Pre-Learning & Post-Learning \\
\hline Strongly agree (5) & $6.4 \%$ & $16.7 \%$ \\
\hline Agree (4) & $56.4 \%$ & $75.9 \%$ \\
\hline Neither agree nor disagree (3) & $20.5 \%$ & $5.6 \%$ \\
\hline Disagree (2) & $15.4 \%$ & $1.9 \%$ \\
\hline Strongly disagree (1) & $1.3 \%$ & $0.0 \%$ \\
\hline & Average = 3.51 & Average = 4.07 \\
\hline & SD $=\mathbf{0 . 8 8}$ & SD $=\mathbf{0 . 5 4}$ \\
\hline \multicolumn{2}{|c|}{$\boldsymbol{p}=\mathbf{0 . 0 0 0 0 0 6 8}$} \\
\hline
\end{tabular}

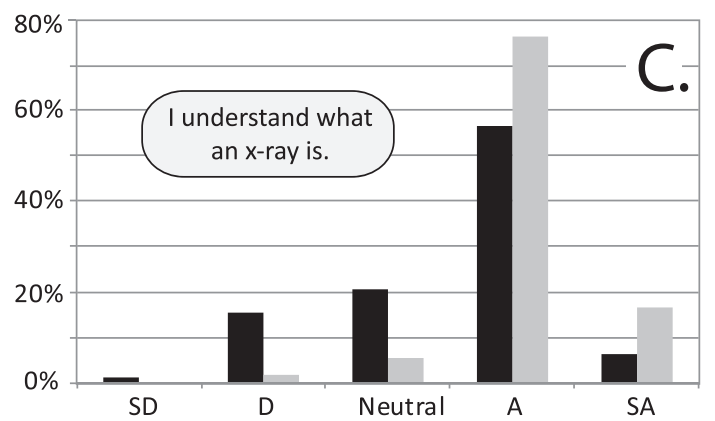

\begin{tabular}{|l|c|c|}
\hline I understand the basic relationship & & \\
\hline between electron shells and energy. & Pre-Learning & Post-Learning \\
\hline Strongly agree (5) & $9.0 \%$ & $20.4 \%$ \\
\hline Agree (4) & $29.5 \%$ & $70.4 \%$ \\
\hline Neither agree nor disagree (3) & $26.9 \%$ & $7.4 \%$ \\
\hline Disagree (2) & $32.1 \%$ & $1.9 \%$ \\
\hline Strongly disagree (1) & $2.6 \%$ & $0.0 \%$ \\
\hline & Average $=\mathbf{3 . 1 0}$ & Average $=\mathbf{4 . 0 9}$ \\
\hline & SD $=\mathbf{1 . 0 4}$ & SD $=\mathbf{0 . 5 9}$ \\
\hline & $\boldsymbol{p}=\mathbf{0 . 0 0 0 0 0 0 0 0 0 0 0 9 0}$ \\
\hline
\end{tabular}

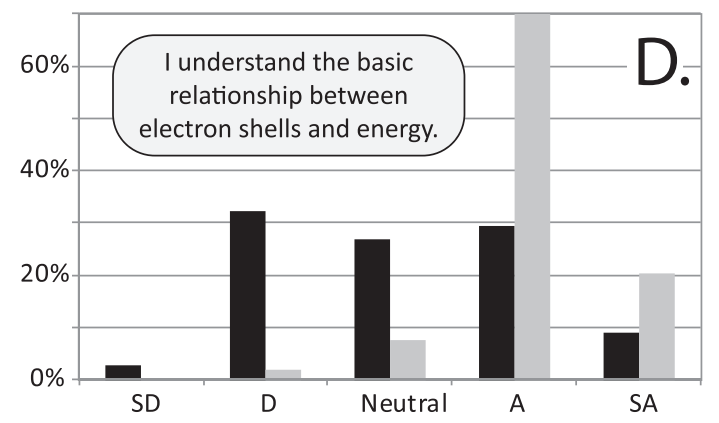

FIGURE 3: Likert scale pre- and postlearning student-response data. In graphs, black bars represent prelearning responses, and gray bars represent postlearning responses.

6B), students also included peer review and check hypothesis as two additional steps prior to the conclusion. In the case of the circular flow charts (Fig. 5), conclusion formulation leads back to the "initial" step.

Most student teams did not include the development of theories or laws in their responses to this free-response opportunity. Those who did include theory development as part of the "conclusion" stage suggest that once a hypothesis is proven reproducible multiple times, it becomes a theory.
During subsequent student discussion of the terminology used by scientists (during the same laboratory meeting period), it became apparent that students considered a "proven" hypothesis (i.e., reproducible by multiple other scientists) to be a theory. Most students also considered scientific theories a matter of opinion, since they had not been proven true. Importantly, students considered a theory that had been proven true to be a law, and a law was an absolute fact that could not be questioned. We believe that 
Example student responses

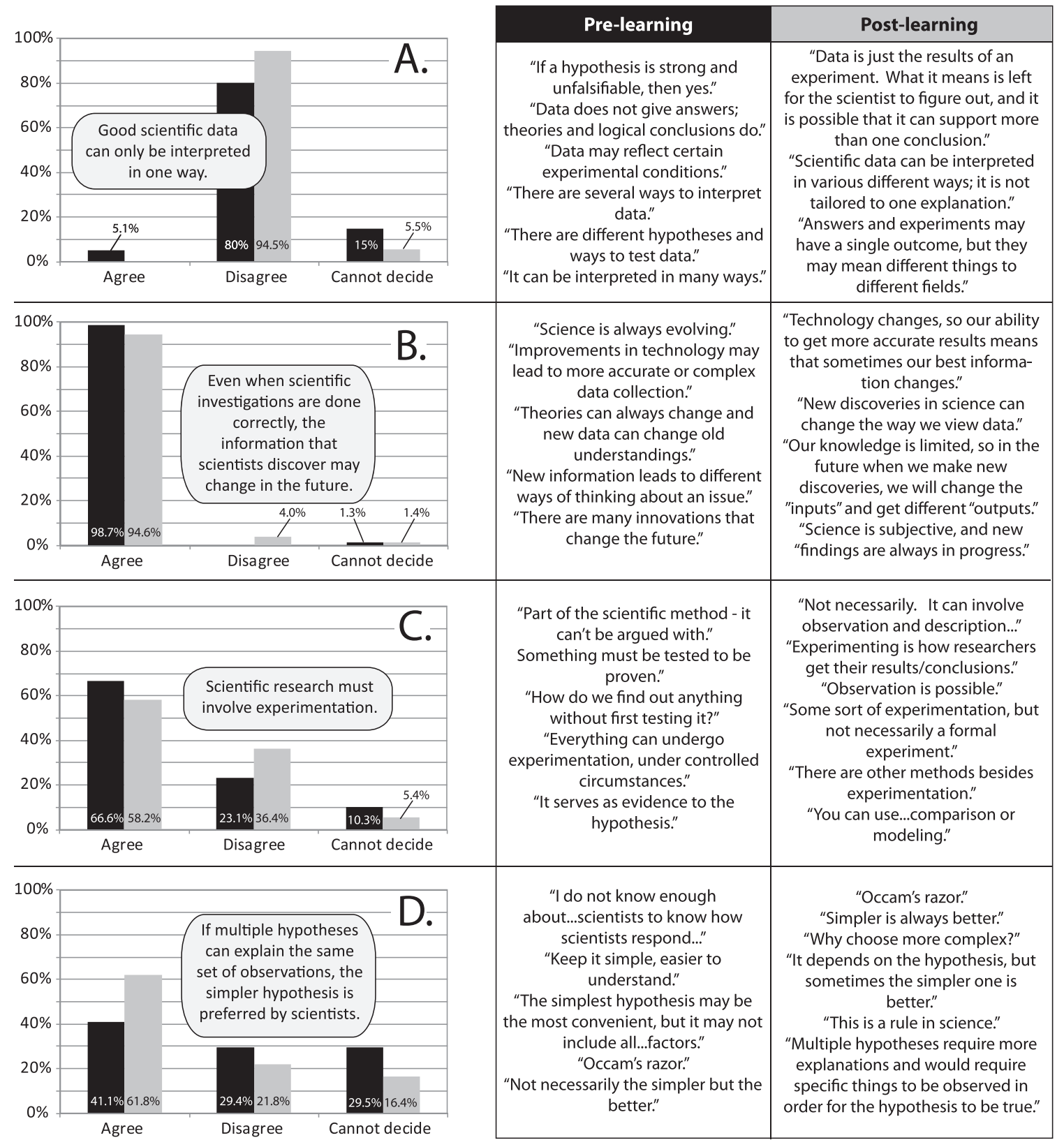

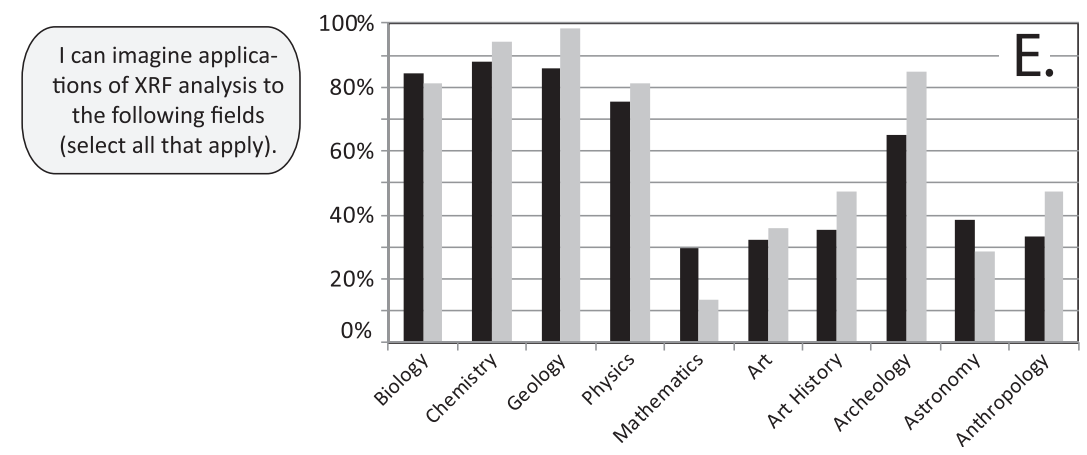

FIGURE 4: Pre- and postlearning student-response data. In graphs, black bars represent prelearning responses, and gray bars represent postlearning responses. 


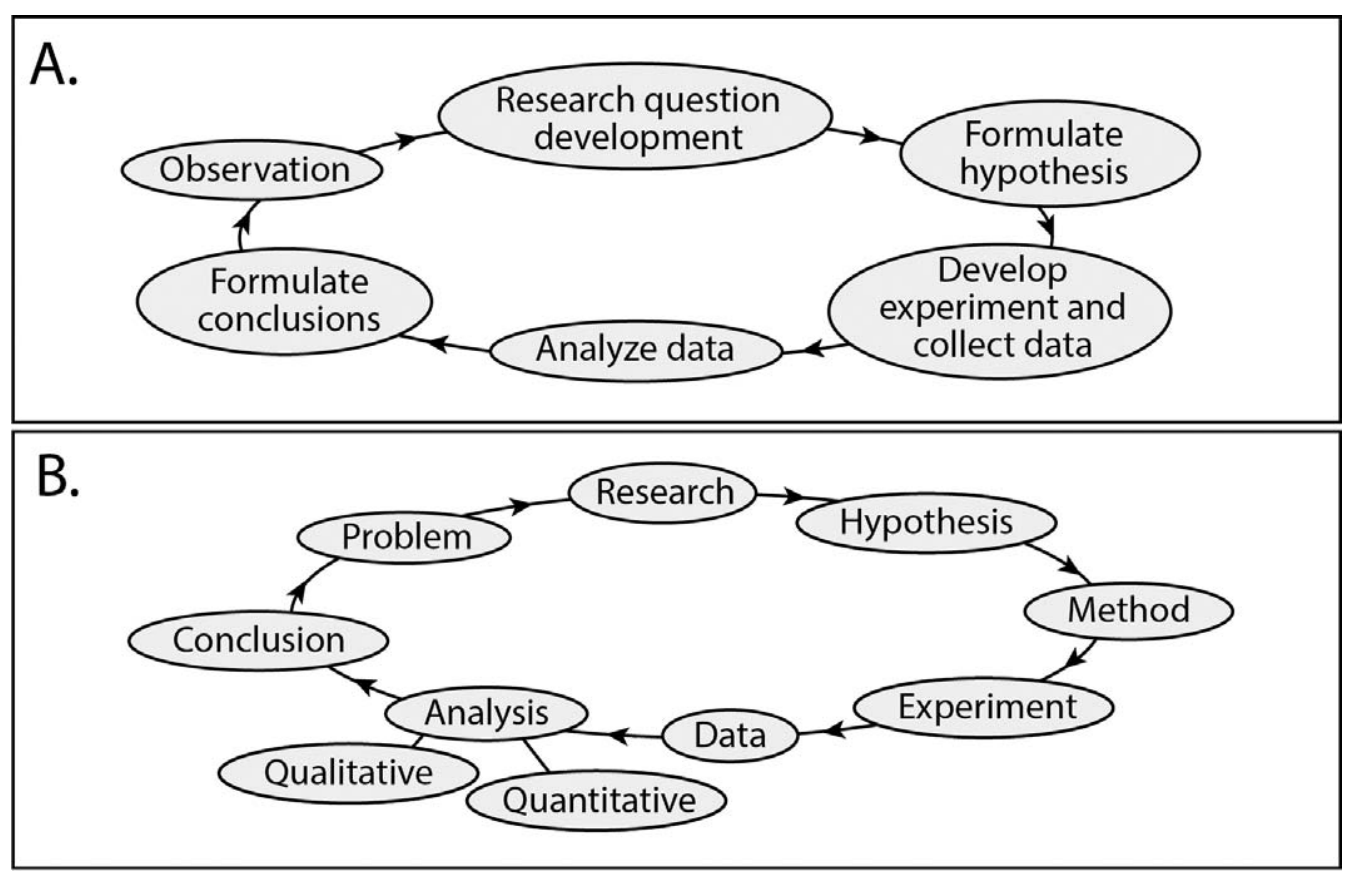

FIGURE 5: Two samples of student-authored circular-style scientific process flow charts.

the omission of theory and law from most student flow charts was influenced by class discussion that led in to the activity.

\section{Trinity Rock/Soil Project Introduction (Prelearning)}

As described in the "Curricular Revision" section, we developed a new interdisciplinary project about soil development on the Trinity University campus. This activity was intended to be an introduction to the process of science as practiced in the real world. To provide context, we focused on Fig. 1, spending significant time discussing the ideas near " $\mathrm{A}$ " on the graphic, so that subsequent student observations and question formulation could be placed within the scientific process framework. After students were introduced to the framework for the multistage project, students were required to make observations and formulate research questions that could be answered by elemental analysis methods of the soils and bedrock samples from one location.

Each student worked with a partner to author a minimum of five possible research questions. These questions (sample student questions included in Table IV) varied widely in their content and revealed a general lack of understanding both about elemental analysis and about the formulation of good research questions. However, during a subsequent activity (week 4 activity; Table III), instructors chose the best of the student-authored research questions to
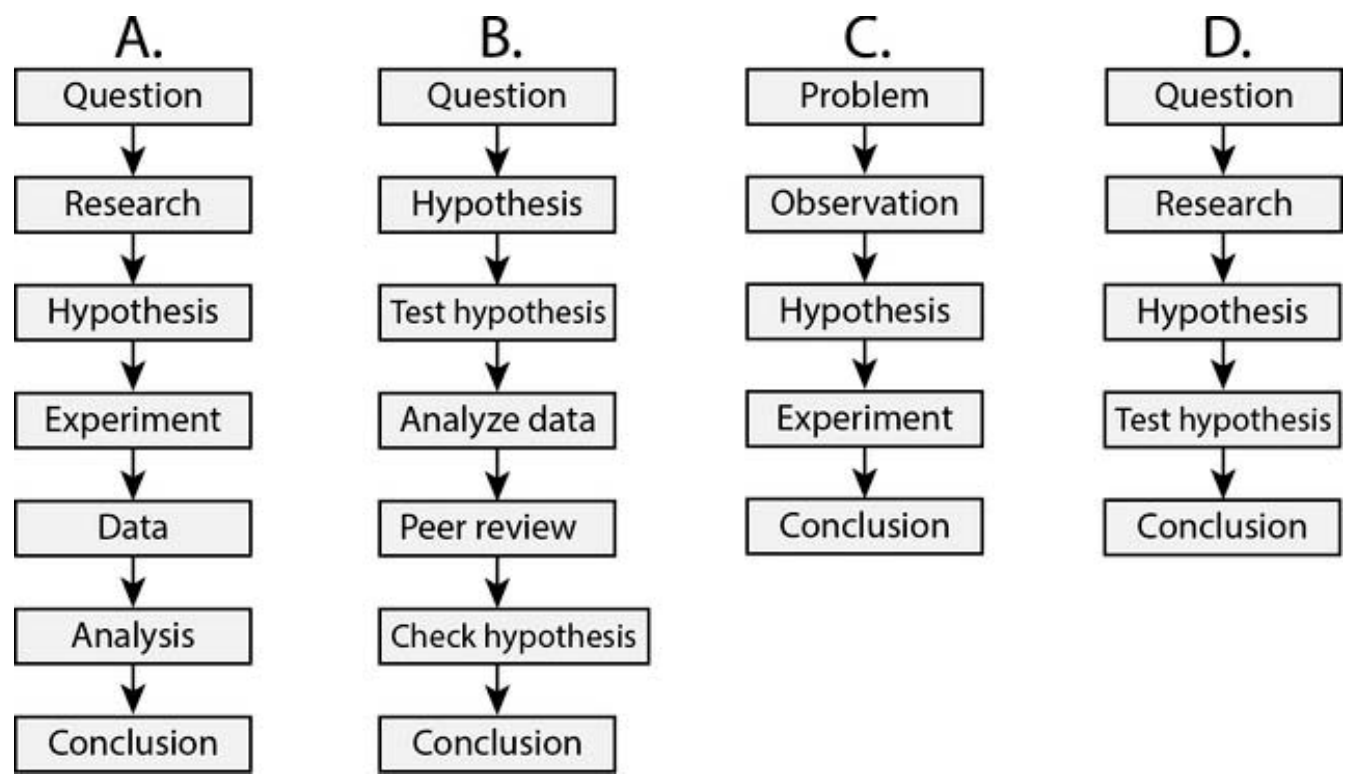

FIGURE 6: Four samples of student-authored linear-style scientific process flow charts. 
TABLE IV: Sample prelearning student research questions for the Trinity soil/bedrock project.

\begin{tabular}{|c|}
\hline What fill was used prior to developing the campus? \\
\hline What is the age difference between the layers? \\
\hline What is the difference in mineral composition of the layers? \\
\hline What are the different thicknesses of the layers? \\
\hline What period is the bedrock from? \\
\hline How many times has construction affected the soil? \\
\hline $\begin{array}{l}\text { How is the soil closer to the bedrock different compared to soil at the } \\
\text { top? }\end{array}$ \\
\hline Does the location affect the composition of samples? \\
\hline Is there a higher rock concentration closer to the bedrock? \\
\hline Why does the soil start on top of the bedrock? \\
\hline What did the area look like 50 years ago? \\
\hline
\end{tabular}

lead students to develop good, testable hypotheses, which were then used to guide the later ICP-OES analysis activity (Table III; week 9 postlearning activity).

\section{Trinity Soil/Rock Project: ICP-OES Analysis (Postlearning)}

In an earlier activity, students obtained elemental data using XRF analysis of the soils and rocks (week 4 activity; Table III). Although qualitative, this analysis did provide students information about the relative concentrations of elements in the rock and soil samples analyzed. Based on these data, students developed hypotheses that they thought could be tested with quantitative analysis by ICP-OES analysis (see four examples of student-authored hypotheses from week 4 activity in Table V). With this elemental information, students in a linked chemistry course analyzed eight elements present in the soils and bedrock ( $\mathrm{Mn}, \mathrm{Sr}, \mathrm{Ti}$, $\mathrm{Zn}, \mathrm{Ni}, \mathrm{Cu}, \mathrm{Fe}$, and $\mathrm{Ca}$ ) by ICP-OES. The elemental concentrations from these analyses were then provided to students in the physical geology laboratory course for this week 9 activity).

In this week 9 activity (Table III), students in the physical geology laboratory analyzed the ICP-OES data in order to evaluate initial hypotheses using those data, come to some initial tentative conclusions, and develop new hypotheses based on both the original XRF data and the new ICP-OES data (Table V). Each student worked with a partner to use the data provided to answer the questions posed. Finally, students thought about how these newly developed hypotheses might be tested, assuming unlimited resources. We include sample student responses in Table V.

\section{Scientific Process Quiz (Postlearning)}

We designed this brief assessment tool to help us determine whether students still held many of the common misconceptions that we observed earlier in the course. Although the quiz also included questions about absolute

TABLE V: Student-authored hypotheses, questions, and sample student responses from ICP-OES analysis activity (week 9 activity in Table III).

\begin{tabular}{l} 
Student-authored hypotheses to be evaluated by students: \\
A) The soil is derived from the limestone. \\
\hline B) The soil is not derived from the limestone. \\
\hline C) The soil samples closer to the surface have higher concentrations of most elements. \\
\hline D) The soil has a lower concentration of Ca than the limestone. \\
\hline
\end{tabular}

1. Describe any trends or patterns you see in the data (students were given elemental data in ppm).

"Zn, $\mathrm{Ni}$, and $\mathrm{Cu}$ are the least abundant elements throughout the soil layers." "Ti increases in abundance with depth." "Cu decreases as it approaches bedrock." "More Zn as it got closer to the surface." "Less Ni in [sample] B, with no data for C or D."

2. Are these data consistent with any of the hypotheses presented (see four student-authored hypotheses, above)? Do these data disprove any hypothesis? Explain your answers.

See student-authored hypotheses and responses in Supplemental Materials.

3. Given these new data, what interpretations can you make about the relationships among bedrock, soil, and human activities?

"The bedrock is the oldest and most accurate example of the original composition of the area. Based on the relatively close relationship of amounts of particular elements between samples $C$ and $D$, it can be implied [inferred] that the composition of the bedrock helps to determine the composition of the overlying soil. At the same time, human activity has definitely affected the upper layers of soil as seen by the higher amounts of certain elements that are not in abundance in the bedrock."

"There is not really a clear trend. Some [elements] increase as they get closer to the bedrock while some decrease. Since that is the case so soil might be more affected by the bedrock while certain [samples] are more affected by human activities as evidenced by [elemental] concentrations."

4. Develop a new hypothesis that is consistent with all observations and data. You can either modify one of the existing hypotheses or write a new one.

"Human activity has altered the elemental (and chemical) composition of the soil." "Human activity has altered the top 2 layers of soil." "The $\mathrm{Ca}$ in the soil was derived from the limestone, whereas the other elements were derived from human interactions with the soil." "There is something besides depth that affects [elemental] concentrations in soil because the [elemental] concentration var(ies) so much with each sample. So human activity might be a cause of this variation."

5. How could you test your new hypothesis with quantitative analysis, assuming unlimited resources?

"Have two soil samples; one that is affected by humans, one that is not and see how they are different." "You could use the XRF to analyze the elemental composition of fertilizer used at Trinity to see if it matches the elements found in the soil." 
TABLE VI: Questions from postlearning scientific process quiz.

\begin{tabular}{|c|}
\hline Uniformitarianism is: \\
\hline a. the principle that best explains why all sedimentary rocks are deposited at the same rate. \\
\hline b. the opposite of catastrophism. \\
\hline c. the longest word in the English language. \\
\hline d. best phrased, "the present is the key to the past." \\
\hline e. both $b$ and $c$. \\
\hline A theory is: \\
\hline a. a tenuous explanation for a specific observation. \\
\hline b. an explanation for natural phenomena that is logical, testable, and predictive. \\
\hline c. an educated guess by a scientist. \\
\hline d. the next step in the process of science, after a hypothesis is developed. \\
\hline e. not well supported by evidence; only when enough evidence is gathered will a theory become a law. \\
\hline Research methods: \\
\hline a. include experimentation, modeling, observation, and comparison. \\
\hline b. are utilized almost exclusively in laboratory settings. \\
\hline c. are virtually identical from scientific discipline to scientific discipline. \\
\hline d. have remained largely the same over the past 150 years. \\
\hline e. usually involve bubbling vials, with occasional explosions. \\
\hline True/False statements: \\
\hline A theory cannot become a law. \\
\hline The important questions that are investigated by scientists are not affected by government funding priorities. \\
\hline $\begin{array}{l}\text { Since nearly all life that has existed in the past is well-preserved in the rock record, we should be able to completely construct the evolution of all } \\
\text { life, if given enough time. }\end{array}$ \\
\hline A hypothesis becomes a theory once that hypothesis is supported and published in the scientific literature. \\
\hline
\end{tabular}

age dating, we used these questions (Table VI) to help guide a class discussion about the scientific process, which immediately followed the quiz. Students performed remarkably well on the quiz, scoring an average of 8 out of 9 points, and subsequent student discussion revealed that students better recognized the complexity of the scientific process, as practiced in the real world. In fact, students commonly referred directly to the scientific process graphic of Carpi and Egger (2010) (Fig. 1) to help make their points.

\section{Practical Exam 2 (Postlearning)}

We authored three questions on the second practical exam in order to measure student learning about different aspects of the process of science. These questions included: (1) Give at least two research methods that you have employed during this course. Explain. (2) Explain why a theory can never become a law, and give one example of a theory (in geology) and one example of a law (in geology). (3) What is peer review, and why is it important to the process of science?

We hoped to assess whether students had learned a more accurate conception of the scientific process, as summarized by Carpi and Egger (2010) (Fig. 1). Importantly, we designed these questions to evaluate specific areas where we had observed common misconceptions about the scientific process in prelearning activities (especially at points A-D on Fig. 1). Since we addressed these concepts using different pedagogical methods throughout the course (Tables III and IV), we thought these questions represented a fair way to both assess the effectiveness of our curricular redesign as well as to provide students opportunity to demonstrate their understanding of the scientific process. Sample student responses are included in the Supplemental Materials.

\section{Postlearning Questionnaire}

Students responded to the same Likert scale questionnaire used for prelearning assessment (see earlier herein). In responding to the statement, "I understand the scientific method," 98.2\% of students selected agree or strongly agree, with a standard deviation of 0.51 from the average of 4.33 (Fig. 3; postlearning responses in gray). Students' responses to the statement, "I know the basic structure of the atom," suggested slightly less student confidence in understanding, as in the prelearning questionnaire, with an average of 4.17 and a standard deviation of 0.64 , but $84.3 \%$ of students did select agree or strongly agree (Fig. 3). For the statement, "I understand what an X-ray is," $92.6 \%$ of students selected agree or strongly agree, with an average of 4.07 and a standard deviation of 0.54 (Fig. 3). Finally, student responses to the statement, "I understand the basic relationship between electron shells and energy," elicited only 90.8\% agree or strongly agree responses, with an average of 4.09 and a standard deviation of 0.59 (Fig. 3).

As with the prelearning questionnaire, students responded to five statements related to the scientific process and elemental analysis (Fig. 4; postlearning responses in gray). In responding to the statement, "Good scientific data 
TABLE VII: Student responses related to XRF and ICP-OES use, as summarized by coauthor Halx.

\begin{tabular}{l} 
"It was interesting seeing the graphs display what was happening on \\
such a small level." \\
\hline "I like the live-action results and the difference between soil in one \\
place and soil in another place that was not very far away." \\
\hline "Who knew there was so much detail in a rock?" \\
"It was very interesting and exciting when we got to use the \\
(instrument)." \\
\hline "It was a lot of fun. We studied what elements were in \\
various. . materials." \\
\hline "The XRF measured the elemental composition of (soil)... which got \\
me to think that dirt is much more interesting than I thought." \\
\hline "We used the XRF to analyze a necklace and saw all of the elements \\
in it. .it was so cool!" \\
\hline "The XRF gives us qualitative measure, while the ICP gives us \\
quantitative." \\
"These instruments allow for inclusion of more information in our \\
analysis."
\end{tabular}

can only be interpreted in one way," $94.5 \%$ of students disagreed, with no students agreeing with the statement; $94.6 \%$ of students agreed with the statement, "Even when scientific investigations are done correctly, the information that scientists discover may change in the future." Students responding to the statement, "Scientific research must involve experimentation," selected agree $58.2 .6 \%$ of the time, while $36.4 \%$ selected disagree, and 5.4\% could not decide. Finally, $61.8 \%$ of students agreed with the statement, "If multiple hypotheses can explain the same set of observations, the simpler hypothesis is preferred by scientists," while $21.8 \%$ disagreed, and $16.4 \%$ could not decide. Students also select all fields (e.g., biology, chemistry, geology) for which they thought $X$-ray fluorescence analysis could be applied to answer research questions (Fig. 4).

Finally, student responses to the statement, "I can imagine the applications of XRF analysis to the following fields (select all that apply)," reveal that students had changed their ideas about the applicability of XRF analysis to different disciplines (Fig. 4E). For biology, mathematics, and astronomy, students saw less applicability postlearning relative to prelearning, while for all other disciplines shown (including geology), a higher percentage of students could imagine the application of elemental XRF analysis to research questions postlearning relative to prelearning (Fig. $4 \mathrm{E})$.

\section{Summative External Evaluation}

Halx (coauthor) was responsible for the collation of information summarized in Figs. 3 and 4 . His review of student free-response information revealed that prior to course activities, students had little to no idea about the capability of the instruments, while postlearning responses suggested a marked increase in engagement directly tied to instrument use. Table VII provides a number of samples of student free-response data, which support his claim. In fact, according to Halx, it was clear that the instruments not only enhanced learning, but also made it more fun.

Halx also addressed our success in achieving the learning goals of the funded NSF project, especially with regard to the impact of XRF and ICP-OES instrument use on those learning goals. Halx posits that these instruments engaged students more fully in the process of science, with instrument use leading to a more engaged classroom and laboratory activity than would have been possible without their use. Based on the significant improvement revealed in the students' explanations of elemental analysis and spectroscopy from the pre- to the postlearning questionnaires, and their answers to embedded exam questions and quizzes (as assessed by faculty members), Halx concluded that instrument use, when combined with a revised curricular context, led to a greater depth of understanding of elemental analysis and spectroscopy than previously reported student laboratory experiences.

\section{IMPLICATIONS OF PRE- AND POSTLEARNING ASSESSMENT}

We believe that the initiative's three primary objectives, listed in "A New Scientific Literacy Initiative" section, were successfully met. Next, we discuss the implications of student assessment results as they pertain to each of the objectives. These inter-related student learning goals can be tied directly to Trinity University's understanding natural science and technology requirement (see "Study Population and Setting" section).

\section{Objective 1: Improving Student Understanding of the Scientific Process and the Nature of Science}

The pre- and postlearning questionnaires reveal the most obvious changes in both student attitudes about science and perceived understanding of the scientific process (Figs. 3 and 4). Interestingly, of the Likert scale statements in Fig. 3, student responses to the statement, "I understand the scientific method," changed the least, with only a small (0.29) increase in the level of agreement with the statement from pre- to post-test (Fig. 3A). However, the standard deviation dropped 0.20 between pre- and postlearning questionnaires, primarily due to a change from $15.3 \%$ of students selecting disagree or neutral on the prelearning questionnaire relative to only $1.9 \%$ on the postlearning questionnaire. We interpret this as a significant change because student perception of the scientific method prior to enrolling in the physical geology laboratory course was based on the erroneous idea that all scientists engage in a static and relatively linear research process.

In fact, the scientific method construction activity revealed that most students thought that all scientists work in a similar manner that could only involve experimental research, thought that research leads to an inevitable "conclusion" (Figs. 5 and 6), and rarely mentioned "theory" or "law" in their flow charts. We believe that students were affected by a discussion that preceded the activity, which likely explains why student flow charts did not include either of these terms. Before this activity, instructors led a discussion about the stereotyping of scientists. Students, as expected, consistently describe a scientist as male, Caucasian, wearing eyeglasses, with disheveled hair, in a white lab coat, and holding a beaker.

Based on student responses on the subsequent activity, which in most cases did not include the terms theory or law, we believe that students focused on the work of an isolated scientist in a laboratory setting. Postactivity discussion 
revealed that students thought that hypotheses led to theories, which when "proven," became laws. Therefore, we believe that student responses on the prelearning questionnaire did not reveal an understanding of the scientific method practiced by scientists in the real world, but instead reflected the very linear and static idea perpetuated in many textbooks (e.g., McComas, 1998). We also believe that our instructions on the handout likely impacted student responses (i.e., "explain the scientific method using a flow chart to aid your explanation"); we chose this phrasing in order to make clear what we were asking of students, so that the instructor would not be required to explain what we were asking of students (thinking, ironically, that an instructor's explanation might bias the responses). We consider the relatively small numerical increase in student-perceived understanding of the scientific method to be much more significant, with the postlearning questionnaire indicating that students had a better understanding of how science works in the real world (Fig. 1), including the basic terminology of science, the research methods employed, and the relationships among the terms hypothesis, theory, and law.

This hypothesis is supported by student responses on the scientific process quiz, where students addressed research methods, the meanings and relationships among hypothesis, theory, and law, and other aspects of the scientific process (Table VI). By this point in the course (week 11; Table III), students had been repeatedly exposed to and engaged in activities that related directly to these concepts, so this result was not surprising. However, student responses on the postlearning questionnaire (week 15; Table III) suggest that the high student scores on the scientific process quiz were not a true indicator of all students' longterm retention and learning.

For some statements related to the scientific method, many students' postlearning understanding of some concepts related to the scientific process did not significantly change. In Figs. 4A and 4B, student pre- and postlearning responses suggest that most students considered good scientific data to be open to interpretation both before and after learning activities (Fig. 4A), and Fig. 4B suggests that students understood that the information revealed by scientific research may change in the future, with nearly identical results before and after laboratory activities. These data reveal that although students initially (prelearning) considered the scientific process to be relatively static and linear, after taking the course, students understood that science is dynamic. Therefore, we do not consider the relatively similar pre- and postlearning responses to refute an overall improvement of student understanding.

However, student postlearning responses to the statement, "Scientific research must involve experimentation," remained dominated by agree, although there was a significant increase in the number of students who disagreed with the statement (Fig. 4C). We assume that these responses reveal a preconceived notion that is difficult to change; the majority of students who participated in this course still see a scientist as someone who must use experimentation to perform research. Finally, student postlearning responses to the statement, "If multiple hypotheses can explain the same set of observations, the simpler hypothesis is preferred by scientists," revealed that the majority of students understand the concept of Occam's razor. However, many students seem to consider the choice of hypotheses to be case dependent (Fig. 4D).

Importantly, when given the opportunity to formulate their own hypotheses related to real data (ICP-OES analysis activity; Table V), students used what they had learned to both interpret physical and chemical processes ( 3 in Table V) and develop new, valid hypotheses based on those data (4 in Table V). When combined with student responses on the second practical exam in the course (Practical Exam II; Table III), it also appears that students better understood the research methods used by scientists, the relationships among hypotheses, theories, and laws, and the role of peer review in the process of science (student responses are included in the Supplemental Materials for Practical Exam II, available at: http://dx.doi.org/10.5408/13-073s3).

\section{Objective 2: Improving Student Understanding of Quantitative and Qualitative Elemental Analyses}

Student responses to Likert scale statements shown in Figs. 3B, 3C, and 3D reveal perhaps the most striking and quantifiable improvements of student understanding of elemental analyses. In response to each statement, the average postlearning values increased significantly, with significantly lower standard deviations. The distribution of response populations displays differences that are statistically significant, with $p$ values of $0.0032,6.8 \times 10^{-7}$, and 9.0 $\times 10^{-12}$ ( $p=1$ indicates identical populations) for responses to statements in Figs. 3B, 3C, and 3D, respectively. The most impressive change in understanding was based on the statement, "I understand the basic relationship between electron shells and energy," with the lowest average prelearning value (of the Likert scale responses) and an improvement of 0.99 from the average of neutral (3.10) to an average of agree (4.09). These fundamental ideas underlie the qualitative and quantitative elemental analyses performed as part of the Trinity rock/soil project.

The multistage Trinity rock/soil project involved qualitative XRF elemental analysis (week 4 activity; Table III) and quantitative ICP-OES analysis (week 9 activity; Table III). Since very few students had performed any sort of elemental analysis prior to enrolling in the physical geology laboratory course, we assume that the quality and accuracy of postlearning student responses are primarily due to students' experiences as part of this course. Based on student responses on these activities (Supplemental Materials and Table V) and instructor-student interactions, students appeared to gain a better understanding about the information that elemental analysis can provide; were more confident in evaluating trends or patterns in elemental data; had improved their abilities to modify and/or formulate testable hypotheses; and understood the limitations of different types of elemental data. These responses were in stark contrast to students' initial attempts to write valid research questions (Table V).

\section{Objective 3: Perceptions of the Applicability of Science to Solve Real-World Problems}

The change in student responses to the statement, "I can imagine the applications of XRF analysis to the following fields (select all that apply)," from the pre- to the postlearning assessment revealed a better, more accurate understanding of the applicability of XRF elemental analysis 
to address problems in different fields. For biology, mathematics, and astronomy, students saw less applicability postlearning relative to prelearning, while for all other disciplines shown (including geology), a higher percentage of students could imagine the application of elemental XRF analysis to research questions postlearning relative to prelearning (Fig. 4E).

In addition, students participated in an authentic soil analysis investigation, thinking about the relative importance of natural and human processes in soil development on Trinity University's campus. In the final step of this project, students developed valid, testable hypotheses based on observational and elemental data (Table V). Based on these responses and instructor-student interactions and the initial research questions posed (Table IV), we believe that postlearning students had a better understanding of how science can address real-world problems. These implications are supported by the work of Wong and Hodson (2009), who advocate the use of authentic scientific practice to provide context for student learning.

\section{A TRANSFERABLE MODEL?}

We believe that this curricular development model, grounded in the results of previous educational research, can be relatively easily transferred to laboratory courses in geosciences programs as well as to laboratory courses in other natural sciences. Based on our course design efforts and assessment results, we have a series of recommendations for science educators interested in either improving an established course or designing a new one. Although we have numbered our recommendations based on our own experiences and the work of previous researchers (documented earlier in this paper), curricular design and revision represent a dynamic process that may vary in the sequence of steps or in the way that feedback is monitored and/or integrated within a given institution or program. Our recommendations:

(1) Outline the primary student learning goals for the course. These learning goals should be authored with assessment in mind (i.e., can a goal, as written, be effectively assessed?) and should be related to both institutional (e.g., Trinity University's general education requirements) and program goals.

(2) Determine how students will demonstrate their achievement of learning goals. Think carefully about what students will produce in the context of the course that can be assessed. These assessment tools could range from a single question on a quiz or exam to a laboratory report to pre- and postlearning questionnaires. In today's age of assessment, this step will likely become part of course design from start to finish. It is likely that the integration of assessment tools within the curriculum will evolve during the course design process, during instruction, and after a course has been taught.

(3) Develop a longitudinal assessment structure that permits frequent feedback using a variety of assessment tools. By designing a course curriculum with frequent assessment using a variety of methods, both students and instructors benefit. Students are more immediately aware of shortcomings in their own understanding, and instructors can identify problems with student achievement before these problems become more significant. Ideally, preand postlearning assessment tools, both those authored by course designers and those validated in the literature (e.g., Aikenhead and Ryan, 1992; Bradford et al., 1995; Libarkin, 2001), should be used to best evaluate the change in student understanding of conceptual or skill-based material.

(4) Incorporate hands-on participation in the gathering and interpretation of data as a significant percentage of student activities. As established in previous research (e.g., Gagne, 1963; Tobin, 1990; O’Neill and Polman, 2004) and in this study, student learning appears to be impacted when students engage in their own scientific data gathering and interpretation.

(5) Ensure that iteration is part of the course structure. The work of Tobin (1990) and the results from this study support a link between student learning and retention with the repetition of both skills and conceptual materials.

(6) Explicitly relate all learning opportunities to the scientific process. Results from this study reinforce the findings of Lederman (2007) and suggest that students will develop a deeper understanding of the scientific process if course activities are always placed within a scientific process framework. The work of Carpi and Egger (2010) aided us tremendously in our efforts.

(7) Integrate opportunities for both critical thinking and student reflection. Our study supports the results of previous research, suggesting that both critical thinking (e.g., Jurecki and Wander, 2012) and reflection (e.g., Schwartz et al., 2004) are important components of the learning process. With opportunities to critically evaluate and reflect on their own activities, we believe that students are more likely to recognize their own participation in the scientific process and consequently improve their own scientific literacy.

(8) If possible, involve an external evaluator early in the course development process. This will make course curricular and assessment design a more thoughtful and robust process. As course designers, faculty do not usually consider how an evaluator outside of their department or program would assess the achievement of student learning goals or the overall success of curricular changes.

(9) If possible, provide learning opportunities that involve the use of research-grade instrumentation. As established by previous researchers (Nakhleh and Krajcik, 1993, 1994; Richter-Egger et al., 2010) and this study, there appears to be a positive link between the use of this instrumentation and student learning. We believe that instructors can better engage students by providing an explicit scientific process context for such a learning opportunity, stressing that such an instrument can be used by scientists to build on our understanding of physical and/or chemical processes in the natural world. 


\section{CONCLUSIONS}

We aimed to improve the scientific literacy of students in the physical geology laboratory course, a $3 \mathrm{~h}$, stand-alone course offered by the department of geosciences at Trinity University. We used a combination of significant curricular revision and the integration of research-grade instrumentation into class activities to achieve overarching learning goals related to the scientific process and the nature of science, quantitative and qualitative elemental analysis, and the application of scientific research to real-world problems. Coupled with these changes, we embedded a wide range of assessable learning opportunities related to the scientific process throughout the course. We focused primarily on prelearning activities early in the course and postlearning activities near the end of the course to measure the changes in student understanding related to laboratory activities.

Student data indicate that our efforts have been largely successful. These successes support the idea that hands-on participation (e.g., Gagne, 1963; AAAS CSE and Gagne, 1965; O'Neill and Polman, 2004), interpretation, and iteration (Tobin, 1990) are key components to effective student learning in the sciences. Importantly, we posit that by explicitly relating these student learning opportunities to the scientific process (as summarized by Carpi and Egger, 2010), we have provided an effective path toward improved student scientific literacy, an idea supported by many researchers (e.g., Cashin and Downey, 1995; Smart and Ethington, 1995; Lederman, 2007).

By including activities related to the Trinity rock/soil project, we provided students with an opportunity to think critically about data and the interpretation of that data, an important and commonly overlooked component of the scientific process (Jurecki and Wander, 2012). In addition, student responses reveal that the integration of the XRF and ICP-OES into the physical geology laboratory, in the context of the Trinity rock/soil project, aided student learning about elemental analysis and spectroscopy, an idea proposed by researchers in introductory chemistry laboratory courses (Nakhleh and Krajcik, 1993, 1994; Richter-Egger et al., 2010).

Although we focused here on the application of these ideas to a physical geology laboratory course, we believe that this model can be easily transferable to any introductory laboratory course that includes scientific literacy as a primary learning goal. By integrating course revision, assessment framework development, and the application of researchgrade instrumentation to project-based learning opportunities, student learning and related scientific literacy should inevitably improve.

\section{Acknowledgments}

This study was made possible by NSF-TUES award \#0942940. This study was also supported by the Trinity University departments of geosciences and chemistry. Thanks go to geosciences department faculty who participated in different aspects of this study, including Les Bleamaster, Glenn Kroeger, Dan Lehrmann, Tony Perez, Diane Smith, and Kathy Surpless. Special thanks go to Anne Egger at Central Washington University, who provided excellent and concise feedback on drafts of the manuscript. Thanks also are due for comments from two anonymous reviewers and the editors at the Journal of Geoscience Education, which helped improve the final version of this manuscript.

\section{REFERENCES}

Abd-El-Khalick, F., and Lederman, N.G. 2000. Improving science teachers' conceptions of the nature of science: A critical review of the literature. International Journal of Science Education, 22:665-701.

Aikenhead, G.S., and Ryan, A.G. 1992. The development of a new instrument: Views on science-technology-society (VOSTS). Science Education, 76:477-491.

Alters, B., and Nelson, C. 2002. Perspective: Teaching evolution in higher education. Evolution, 56:1891-1901.

American Association for the Advancement of Science (AAAS). 1993. Benchmarks for science literacy. New York: Oxford University Press.

American Association for the Advancement of Science (AAAS) Commission of Science Education (CSE) and Gagne, R. 1965. The psychological basis of science: A project approach: Washington, DC: AAAS. p. 35.

American Association for the Advancement of Science, Project 2061, Rutherford, F., and Ahlgren, A. 1994. Science for all Americans. New York: Oxford University Press. p. 272.

Atmospheric Science Literacy Framework. 2007. Atmospheric science literacy-Essential principles and fundamental concepts of atmospheric science. Available at http://eo.ucar.edu/ asl/pdfs/ASLbrochureFINAL.pdf (accessed 14 June 2013).

Baird, J. 1990. Metacognition, purposeful enquiry and conceptual change. In Hegarty-Hazel, E., ed., The student laboratory and the science curriculum. London: Routledge, p. 183-200.

Blosser, P. 1983. The role of the laboratory in science teaching. School Science and Mathematics, 83:165-169.

Bradford, C.S., Rubba, P.A., and Harkness, W.L. 1995. Views about science-technology-science interactions held by college students in general education physics and STS courses. Science Education, 79:355-373.

Bybee, R. 2000. Teaching science as inquiry. In Minstrel, J., and Van Zee, E.H., eds., Inquiring into inquiry learning and teaching in science. Washington, DC: AAAS, p. 20-46.

Carpi, A., and Egger, A. 2010. The process of science. New Canaan, CT: Visionlearning, Inc. p. 216.

Cashin, W.E., and Downey, R.G. 1995. Disciplinary differences in what is taught and in students' perceptions of what they learn and of how they are taught. New Directions for Teaching and Learning, 64:81-92.

Culliton, B. 1989. The dismal state of scientific literacy. Science, 243:600.

Deng, F., Chen, D., Tsai, C., and Chai, C. 2011. Students' views of the nature of science-A critical review of research. Science Education, 95:961-999.

Denzin, K. 1989. The research act: A theoretical introduction to sociological methods, 3rd ed. Englewood Cliffs, NJ: Prentice Hall. p. 306

Driver, R., Leach, J., Millar, R., and Scott, P. 1996. Young people's image of science. Buckingham, UK: Open University Press. p. 172.

Driver, R., Newton, P., and Osborne, J. 2000. Establishing the norms of scientific argumentation in classrooms. Science Education, 84:287-312.

Durant, J. 1993. What is scientific literacy? In Durant, J.R., and Gregory, J., eds., Science and culture in Europe. London: Science Museum, p. 129-137.

Earth Science Literacy Initiative. 2010. Earth Science literacy principles-The big ideas and supporting concepts of Earth Science. Available at http://www.earthscienceliteracy.org/ es_literacy_6may10_.pdf (accessed 14 June 2013).

Gagne, R. 1963. The learning requirements for enquiry. Journal of Research in Science Teaching, 1:144-153.

Guerra-Ramos, T., Ryder, J., and Leach, J. 2010. Ideas about the nature of science in pedagogically relevant contexts-Insights from a situated perspective of primary teachers' knowledge. Science Education, 94:282-307. 
Hofstein, A., and Lunetta, V.N. 2003. The laboratory in science education: Foundations for the twenty-first century. Science Education, 88:28-54.

Jenkins, E. 1994. Scientific literacy. In Husen, T., and Postlethwaite, T.N., eds., The international encyclopedia of education, vol. 9. Oxford, UK: Pergamon Press, p. 5345-5350.

Jurecki, K., and Wander, M. 2012. Science literacy, critical thinking, and scientific literature-Guidelines for evaluating scientific literature in the classroom. Journal of Geoscience Education, 60:100-105.

Keeter, S., Smith, G., and Masci, D. 2007. Religious belief and public attitudes about science in the U.S. International indicators of science and the public. London, UK: The Pew Research Center.

Latour, B. 1987. Science in action. Cambridge, MA: Harvard University Press. p. 288.

Laugksch, R. 2000. Scientific literacy-A conceptual overview. Science Education, 84:71-94.

Leach, J. 2002. Students' understanding of the nature of science and its influence on labwork. In Psillos, D., and Niedderer, H., eds., Teaching and learning in the science laboratory. Dordrecht, Netherlands: Kluwer Academic Publishers, p. 41-48.

Leach, J., Millar, R., Ryder, J., and Séré, M.G. 2000. Epistemological understanding in science learning: The consistency of representations across contexts. Learning and Instruction, 10:497527.

Lederman, N.G. 2007. Nature of science: Past, present, and future. In Abell, S.K., and Lederman, N.G., eds., Handbook of research on science education. Mahwah, NJ: Lawrence Erlbaum and Associates, p. 831-880.

Lederman, N.G., Wade, P.D., and Bell, R.L. 1998. Assessing the nature of science: What is the nature of our assessments? Science Education, 7:595-615.

Libarkin, J.C. 2001. Development of an assessment of student conception of the nature of science. Journal of Geosciences Education, 49:435-442.

McComas, W.F. 1998. The principal elements of the nature of science-Dispelling the myths. In McComas, W.F., ed., The nature of science in science education. Dordrecht, Netherlands: Kluwer Academic Publishers, p. 53-70.

Millar, R., and Osborne, J. 1998. Beyond 2000: Science education for the future. London: King's College. p. 32.

Miller, J. 2010a. The conceptualization and measurement of civic scientific literacy for the 21st century. In Meinwald, J., and Hildebrand, J., eds., Science and the educated American-A core component of liberal education. Cambridge, MA: American Academy of Arts and Sciences, p. 241-255.

Miller, J. 2010b. Adult science learning in the Internet era. Curator, 53:191-208.

Miller, J. 2012. What colleges and universities need to do to advance civic scientific literacy and preserve American democracy. Liberal Education, Fall 2012:28-33.

Nakhleh, M., and Krajcik, J. 1993. A protocol analysis of the effect of technology on students' actions, verbal commentary, and thought processes during the performance of acid-base titrations. Journal of Research in Science Teaching, 30:1149-1168.

Nakhleh, M., and Krajcik, J. 1994. Influence of levels of information as presented by different technologies on students' understanding of acid, base, and $\mathrm{pH}$ concepts. Journal of Research in Science Teaching, 31:1077-1096.

National Research Council (NRC). 1996. National science education standards. Washington, DC: National Academy Press.

National Science Teachers Association. 1982. Science-technologysociety: Science education for the 1980s (an NSTA position statement). Washington, DC: National Science Teachers Association.
Nelson, K., Huysken, K., and Kilibarda, Z. 2010. Assessing the impact of geoscience laboratories on student learning-Who benefits from introductory labs? Journal of Geoscience Education, 58:43-50.

Ocean Literacy Framework. 2013. Ocean literacy: The essential principles of ocean sciences for learners of all ages, version 2. Available at http://www.coexploration.org/oceanliteracy/ documents/OceanLitChart.pdf (accessed 14 June 2013).

O'Neill, D., and Polman, J. 2004. Why educate "little scientists?" Examining the potential of practice-based scientific literacy. Journal of Research in Science Teaching, 41:234-266.

Patton, M.Q. 2002. Qualitative research and evaluation methods, 3rd ed. Thousand Oaks, CA: Sage Publications. p. 598.

Richter-Egger, D., Hagen, J., Laquer, F., Grandgenett, N., and Shuster, R. 2010. Improving student attitudes about science by integrating research into the introductory chemistry laboratory-Interdisciplinary drinking water analysis. Journal of Chemical Education, 8:862-868.

Roth, W.-M., and Lee, Y.J. 2007. "Vygotsky's neglected legacy": Cultural-historical activity theory. Review of Educational Research, 77:186-232.

Ryder, J., Leach, J., and Driver, R. 1999. Undergraduate science students' images of science. Journal of Research in Science Teaching, 36:201-219.

Saldaña, J. 2009. The coding manual for qualitative researchers. Thousand Oaks, CA: Sage Publications. p. 308.

Sampson, V., and Clark, D.B. 2009. The impact of collaboration on the outcomes of scientific argumentation. Science Education, 93:448-484.

Schwartz, R.S., Lederman, N.G., and Crawford, B.A. 2004. Developing views of nature of science in an authentic context: An explicit approach to bridging the gap between nature of science and scientific inquiry. Science Teacher Education, 88:610-645.

Smart, J.C., and Ethington, C.A. 1995. Disciplinary and institutional difference in undergraduate education goals. New Directions for Teaching and Learning, 64:49-57.

Strauss, A., and Corbin, J. 1998. Basics of qualitative research: Techniques and procedures for developing grounded theory, 2nd ed. Thousand Oaks, CA: Sage Publications. p. 312.

Tobin, K.G. 1990. Research on science laboratory activities-In pursuit of better questions and answers to improve learning. School Science and Mathematics, 90:403-418.

Trinity University. 2013. Courses of study 2013-2014. San Antonio, TX: Trinity University. Available at http://web.trinity.edu/ x18956.xml (accessed January 2014).

U.S. Climate Change Science Program. 2009. Climate literacy-The essential principles of climate sciences, version 2. Available at http://downloads.climatescience.gov/Literacy/Climate\%20 Literacy\%20Booklet\%20Low-Res.pdf (accessed 14 June 2013).

Van Eijck, M., Hsu, P., and Roth, W. 2008. Translations of scientific practice to "students' images of science." Science Education, 93:611-634.

Wong, S.L., and Hodson, D. 2009. From the horse's mouth: What scientists say about scientific investigation and scientific knowledge. Science Education, 93:109-130.

Wysession, M., LaDue, N., Budd, D., Campbell, K., Conklin, M., Kappel, E., Lewis, G., Raynolds, R., Ridky, R., Ross, R., Taber, J., Tewksbury, B., and Tuddenham, P. 2012. Developing and applying a set of Earth Science literacy principles. Journal of Geoscience Education, 60:95-99.

Zohar, A., and Nemet, F. 2002. Fostering students' knowledge and argumentation skills through dilemmas in human genetics. Journal of Research in Science Teaching, 39:35-62. 